\title{
Lung infection caused by Pseudomonas aeruginosa in a CD26/DPP4 deficient F344 rat model
}

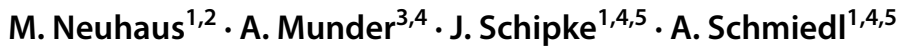

Received: 4 May 2018 / Revised: 27 March 2019 / Accepted: 16 April 2019 / Published online: 14 May 2019

(c) Springer Nature Switzerland AG 2019

\begin{abstract}
Background Pseudomonas aeruginosa $(P A)$ is the most important opportunistic pathogen in causing nosocomial infections and, furthermore, poses a permanent threat for severe chronic infections in patients with cystic fibrosis or COPD. The transmembrane protein CD26 with dipeptidyl peptidase-4 (DPP4) activity shows an increased expression in inflamed tissue. We tested whether CD26/DPP4 deficiency leads to reduced inflammation and decreased structural damage when infected with $P A$. Methods CD26/DPP4 ${ }^{+}$and CD26/DPP4 ${ }^{-}$rats were instilled intratracheally with $\mathrm{NaCl}$ (controls) or with $\mathrm{PA}$. Six hours later, bacterial distribution was detected with the in vivo imaging system 200 (IVIS). Lungs were then processed for molecular biology, light and electron microscopy and analyzed qualitatively, quantitatively and stereologically. Bacterial numbers were determined in homogenized lungs.

Results Compared to saline treated controls, in both infected groups (1) the acinar airspace was significantly increased, (2) the volume density of the alveolar epithelium was significantly decreased, (3) the septal thickness was significantly reduced, (4) more than $40 \%$ of the alveolar epithelial surface was damaged, and up to $36 \%$ of the epithelial surface was covered with edema. In infected CD26- rats, the increase in lung weight was significantly less pronounced, the portion of edematous alveolar airspace was significantly lower and the part of edema interspersed with $P A$ was decreased significantly.

Conclusions CD26/DPP4 deficiency resulted in reduced pulmonary edema under sublethal $P A$ infection, implicating a role for CD26 in infection progression. The partly pronounced structural damage may mask further possible influences of CD26 on the inflammatory response.
\end{abstract}

Keywords Pseudomonas aeruginosa $\cdot$ Lung infection $\cdot$ CD26/DPP4 rat model $\cdot$ Electron microscopy $\cdot$ Surfactant

Responsible Editor: Artur Bauhofer.

A. Schmiedl

Schmiedl.Andreas@mh-hannover.de

1 Institute of Functional and Applied Anatomy, Hannover Medical School, Carl-Neuberg-Straße 1, 30625 Hannover, Germany

2 Department of Oral and Maxillofacial Surgery, Hannover Medical School, Carl-Neuberg-Straße 1, 30625 Hannover, Germany

3 Clinic of Pediatric Pneumology, Allergology and Neonatology Hannover Medical School, Carl-Neuberg-Straße 1, 30625 Hannover, Germany

4 Biomedical Research in Endstage and Obstructive Lung Disease Hannover (BREATH), Hannover Medical School, Hannover, Germany

5 REBIRTH Cluster of Excellence, Hannover Medical School, Hannover, Germany

\section{Introduction}

Pseudomonas aeruginosa (PA), a gram-negative bacterium, causes nosocomial pneumonia [1], predominantly in immunocompromised patients and patients with cystic fibrosis, chronic obstructive pulmonary disease, bronchoectasies or ventilator-associated pneumonia [2]. Antibiotic therapy is limited because of a prevalence of multidrug resistance [1]. The world health organization listed $P A$ in the most critical group of drug-resistant germs [3].

The PA isolate TBCF10839 selected for this study was from a CF patient, from whom it was hardly to eradicate due to biofilm formation and numerous antibiotic resistances. TBCF10839 is non-piliated because of an out-of-frame deletion in the pilQ gene locus [4, 5], but this strain exhibited a deficient motility and a partial surviving in phagosomes due to inefficient killing after engulfing [5]. TBCF10839 was used in different mouse infection models [6-9]. 
Pulmonary surfactant, a mixture of lipids and proteins covers the distal airspaces and reduces surface tension at the air liquid interface. Among the four surfactant proteins (SPB, SP-C, SP-A, SP-D) the both last ones play as collectins an important role in host defense mechanisms of the lung $[10,11]$. They bind and agglutinate various microorganisms and pathogen-derived components, act as opsonins and may possess direct inhibitory effects on bacterial growth. Furthermore, SP-A and SP-D operate with immune cells, activate various cellular functions, and regulate inflammatory cellular responses by associating with cell surface patternrecognition receptors $[10,11]$. It was found that the collectins enhance the clearance of $P A$ by stimulating alveolar macrophages to phagocyte $P A$ and modulate the inflammatory response in the lungs [12].

However, PA produces enzymes, predominantly elastase, which leads to the degradation of SP-A and SP-D as shown by degradation assays with PA and several different clinical isolates obtained from the sputum of patient with cystic fibrosis [13].

The transmembrane glycoprotein CD26/DPP4 (dipeptidyl peptidase-4) is expressed on epithelia and endothelia, as well as on lymphocytes and occurs as a soluble form. The second highest expression of CD26/DPP4 was found in lungs $[14,15]$. CD26/DPP4 is involved in inflammatory processes, because its dipeptidyl peptidase activity cleaves paracrine chemokines such as Rantes (regulated on activation normal $\mathrm{T}$ cell expressed and secreted), stromal cell-derived factor, eotaxin and macrophage-derived chemokine [14, 15]. Interestingly, $\mathrm{NH} 2$ terminal truncation of the chemokine granulocyte chemotactic protein-2 (CXCL6) does not alter the chemotactic activity of neutrophils. $\mathrm{NH}_{2}$ terminal processing of an isoform of macrophage inflammatory peptide $1 \alpha$ (MIP-1 $\alpha)$ increases the chemotactic activity [16]. Furthermore, CD26/DPP4 induces T cell co-stimulation and interleukin-2 (IL-2) production [17]. So co-stimulated T cells may have a particular role in acquired immune reactions, such as antigen specific host defense against different diseases such as infection [18]. Additionally, soluble CD26 enhanced transendothelial T cell migration [19]. There is an association between the degree of inflammation and CD26/ DPP4 expression [20]. Using CD26/DPP4 inhibitors in a lung ischemia/reperfusion model, predominantly a significant improvement of gas exchange, a better preservation of parenchymal ultrastructure and reduced neutrophil infiltration were found [21]. Furthermore, application of an CD26/ DPP4 inhibitor decreased serum DPP4 activity, BAL protein concentration, cell number and pro-inflammatory cytokine levels, and reduced pathological histological findings of lung injury such as edema, neutrophil invasion and disruption of lung tissue in LPS challenged mice lungs [22]. Moreover, a reduced inflammation of lung parenchyma combined with a reduced airway specific recruitment of T-cells [23] and decreased expression of surfactant proteins was found in asthma induced CD26/DPP4 deficient (DPP4/CD26-) rats compared to CD26/DPP4 positive rats (wild types) [24].

Thus, CD26/DPP4 may influence the degree of different inflammations in many and varied ways. However, there is only less information about the influence of CD26/DPP4 expression on the degree of structural preservation and inflammation during infection. It was known that CD26/ DPP4 is a receptor for the Middle East Respiratory Syndrome Coronavirus (MERS-CoV). In a transgenic mouse model globally expressing codon-optimized human dipeptidyl peptidase 4 (hDPP4), MERS-CoV infection aggravated pneumonia and led to multi-organ damage within the first days [25].

So the question arises, whether there is a interrelation between CD26/DPP4 expression and the degree of infection, structural preservation and inflammation as well as expression of collectins in infected lungs.

Therefore, we carried out this study to characterize the pulmonary distribution of PA and to determine the degree of structural alterations in lung parenchyma light and electron microscopically using morphometric methods as well as to determine the expression of collectins with the aim to verify the hypothesis that the lack of CD26/DPP4 activity dampens the degree of $P A$ dependent infection.

\section{Materials and methods}

\section{Animals and bacterial infection}

Adult wild type F344 rats of the inbred strain [F344/Ztm] and CD26/DPP4 ${ }^{-}$rats of the inbred strains [F344/Crl(Wiga) SvH-Dpp4 $\left.{ }^{\mathrm{m}}\right]$ and [F344/DuCrjSvH-Dpp4 ${ }^{\mathrm{m}}$ ] completely lack in CD26/DPP4 activity [26] were used as control and experimental groups. Microbiologic monitoring during breeding and maintenance of the rats were done according to FELASA recommendations, all procedures performed on rats were approved by the local authorities (LAVES, Oldenburg, Germany, file nr.: 0815-24).

Control wild type and CD26/DPP4 deficient rats have been intratracheally instillated with $1 \mathrm{ml}$ sterile $0.9 \% \mathrm{NaCl}$ suspension.

In the experimental group, we used the TBCF10839 strain, a cystic fibrosis (CF) airway germ, whose virulence had been already established $[6,8]$. For in vivo imaging, luminescent derivatives of the strain were generated by integrating a luxCDABE luciferase reporter gene operon into the bacterial chromosome. Therefore, a miniCTX-lacluxplasmid was isolated from recombinant Escherichia coli Topo-one-shot CTX-lac-lux cells [27] and integrated sitespecifically to the attB-site of the $P A$ chromosome via electroporation $[28,29]$. 
The bacteria were grown in LB-(Luria-Bertani) broth overnight to its stationary phase. The suspension was centrifuged at $5000 \mathrm{~g}$ and rinsed with phosphate-buffered saline (PBS). By spectrophotometry at $600 \mathrm{~nm}$ the optical density (OD) was adjusted and the number of colony forming units (CFU) extrapolated from a standard growth curve [6, 9]. For the verification of the CFU an aliquot was plated on LB-agar plates.

$P A$ diluted in sterile PBS $\left(1 \times 10^{10} \mathrm{CFU} / \mathrm{ml}\right)$ suspension were inoculated directly into the trachea of anaesthetized rats as previously described [30]. Control wild type and CD26/ DPP4 deficient rats have been intratracheally instillated with $1 \mathrm{ml}$ sterile $0.9 \% \mathrm{NaCl}$ suspension. After inoculation up to $1 \mathrm{ml}$ air was blown into the lungs to ensure that the whole volume of the bacterial suspension had spread in the lung. A multiparametric score was used to evaluate the animals general condition and the susceptibility to bacterial infection, whereas 0 is unaffected and $>11$ is moribund $[31,32]$. The parameters vocalization, piloerection, attitude, locomotion, breathing, curiosity, nasal secretion, grooming and dehydration were used. Each one has been characterized by the following degrees: 0 (normal), 1 (partly deficient), 2 (deficient), respectively.

\section{In vivo imaging system 2000 (IVIS)}

Bacterial distribution $6 \mathrm{~h}$ after infection was verified additionally with the IVIS 200 [29].

\section{Tissue processing}

$6 \mathrm{~h}$ after inoculation, rats were killed by exsanguination. The trachea was cannulated, the lung dilated with air and the left principal bronchus ligated. After excision the right lung, the liver and the spleen were stored in PBS buffer containing $0.2 \%$ of a tenside solution (IGEPAL CA 630, Sigma), then homogenized and serial dilutions plated for determining organ bacterial numbers [30]. Total viable counts per organ were determined after $24 \mathrm{~h}$ incubation at $37^{\circ} \mathrm{C}$. The left lung was immersion fixed in $1.5 \%$ glutaraldehyde and $1.5 \%$ paraformaldehyde in 0.15 M HEPES buffer for $24 \mathrm{~h}$. Afterwards lung weight and volume via water displacement were determined. After embedding in agar, the lung was cut from apical to basal into equidistant $2 \mathrm{~mm}$ thin slices using a tissue cutter. Samples for light and electron microscopy were processed as described earlier [9].

\section{Quantitative analysis}

Samples were taken randomized to give each area of the lung the same chance to get analyzed [33]. Stereological measurements were carried out on semithin sections using the newCast software on the light microscope Leica DM6000B and using the software Stepanizer ${ }^{\circledR}$ on digital electron microscopic pictures of ultrathin sections, which were taken on the transmission electron microscope Morgani ${ }^{\mathrm{TM}} 2000$ [34].

The following volume densities $\left(V_{\mathrm{V}}\right)$ and surface densities $\left(S_{\mathrm{V}}\right)$ were determined [35]:

Air spaces: $V_{\mathrm{V}}$ (alveoli + alveolar ducts/par).

Alveolar septa: $V_{\mathrm{V}}$ (septa, par), $S_{\mathrm{V}}$ (septa/par).

Airspaces with edema: $V_{\mathrm{v}}$ (edema, airspace).

Absolute volumina and surfaces were determined by multiplying the $V_{\mathrm{V}}$ and $S_{\mathrm{V}}$ with the lung volume.

The mean alveolar septal thickness was determined as septal volume to surface ratio and the alveolar size as alveolar volume to surface ratio. The surface fraction of intact and damaged alveolar epithelium was determined additionally electron microscopically: $S \mathrm{~s}_{\text {epi intact/epi total }}=I_{\text {epi intact }} / I_{\text {epi total }}$ [\%].

\section{Western blot analyses}

Homogenization of frozen lung samples and protein isolation was carried out using NucleoSpin ${ }^{\circledR}$ RNA/Protein assay \#740933.250 (Macherey/Nagel, Düren Germany) as described by the manufacturer. Protein content was determined using the Protein Quantification Assay \#740967.50 (Macherey/Nagel, Düren Germany) according to the manufacturer's protocol. Proteins were separated by $10 \%$ SDS-polyacrylamide gel electrophoresis using $20 \mu \mathrm{g}$ of each sample. Separated proteins were transferred to PVDF membranes after equilibration in ethanol and blotted for $40 \mathrm{~min}$ (400 mA). The blots were incubated with the primary antibody polyclonal anti-SP-A (AB3420-I, Merck Millipore, Darmstadt, Germany, polyclonal antibody SP-D (AntiSFTPD HPA0444582_R40747, Sigma life science, St. Louis, MO, USA) or polyclonal antibody anti- $\alpha$-tubulin (2144, Cell Signaling). The antibodies, diluted in 3\% BSA 1:1000, were incubated overnight. After 15 min rinsing with Tris-buffered saline and Tween20 (TBST), incubation with the secondary antibody goat anti rabbit (111-036-144, Dianova), diluted in 3\% BSA 1:20,000, ensued for $1 \mathrm{~h} .30 \mathrm{~min}$ rinsing in TBST followed by incubation in TBS for $10 \mathrm{~min}$. The protein-antibody complexes were incubated with $10 \mathrm{ml}$ Western Bright enhanced chemiluminiscence (ECL) substrate (Biozym) for detection and visualization in the ChemiDoc Touch Imaging System (Bio-Rad Laboratories, BMBH München, Germany).

Western Blots were evaluated by densitometry and normalized to $\alpha$-tubuline.

\section{Quantitative real-time PCR}

The following primers for the SPs and the housekeeping gene (HKG, $\beta$-Actin), SP-A and SP-D were used as described below: 
$\beta$-Actin (Actb): (fw): ATC CTC TTC CTC CCT GGA GA.

(rev): AGG ATT CCA TAC CCA AGA AGG A. SP-A (fw): CCTGCAGGCTCTGTATGTGG.

(rev): TGCACTTGATACCAGCGACA. SP-D (fw): AGGAAGAATCTGCCATGCT. (rev): AAGACTAGGGTGCACGTGTT.

Frozen lung samples were homogenized using the NucleoSpin ${ }^{\circledR}$ RNA/Protein assay \#740933.250 (Macherey/ Nagel, Düren Germany) according to the manufacturer's guidelines. Determination of RNA content was carried out in the NanoDrop ${ }^{\mathrm{TM}}$ spectral spectrophotometer 2000 (Thermo Fisher Scientific, Braunschweig, Germany). The RNA was reverse transcribed into the complementary DNA using the iScript ${ }^{\mathrm{TM}}$ cDNA Synthesis Kit (\#1708891;Bio-Rad Laboratories, München Germany) according to the manufactures guidelines. Transcript levels of Sps and the house keeping gene were analyzed by qRT- PCR using the $\mathrm{iTaq}^{\mathrm{TM}}$ universal SYBR ${ }^{\circledR}$ Green supermix (Bio-Rad Laboratories, München). We performed the reactions using the CFX384 Touch ${ }^{\text {TM}}$ Real-TimePCR Detection System (BioRad Laboratories, München, Germany). After activation for $3 \mathrm{~min}$ at $95^{\circ} \mathrm{C}, 40$ cycles of $5 \mathrm{~s}$ denaturation at $95^{\circ} \mathrm{C}$ and annealing at $60{ }^{\circ} \mathrm{C}$ for $10 \mathrm{~s}$ followed. Results were expressed as mean $\Delta \Delta \mathrm{Cq}$ values normalized to $\beta$-Actin.

\section{Statistical analysis}

All values are presented as mean \pm SD. Values were tested for significance $(p<0.05)$ by a two-tailed $t$ test or by ANOVA (multiple comparisons), if normal distribution was present or Kruskal-Wallis test, if normality test failed. (Graph Pad Prism 6.0).

\section{Results}

\section{Disorders of general condition}

Using a score characterizing the general health, saline treated controls showed immediately after saline application and after $6 \mathrm{~h}$ an undisturbed general normal condition. Compared to controls PA infected animals exhibited reduced motoric patterns and decreased attention, general conditions were moderately disturbed $2 \mathrm{~h}$ after instillation without significant strain dependent differences and $6 \mathrm{~h}$ after infection the general condition was disturbed extremely. The rats had strong breathing troubles and breathed very irregularly. The CD26/DPP4 ${ }^{+}$rats exhibited a general condition score of $4.8 \pm 1.6(n=12)$ after $2 \mathrm{~h}$ and $8.6 \pm 0.8(n=12)$ after $6 \mathrm{~h}$. The score amounts to $6.3 \pm 1.3(n=12)$ after $2 \mathrm{~h}$ and to $8.9 \pm 0.9(n=12)$ after $6 \mathrm{~h}$ in the CD26/DPP4- rats. Both groups were profoundly troubled and in a bad health condition without statistical differences.

\section{In vivo imaging}

Using the IVIS200, $6 \mathrm{~h}$ after inoculation bacterial infection of the airways and of both lungs was identified without strain dependent alterations (Fig. 1a, b). However, only large numbers of germs could be detected by bacterial luminescence.

Ex vivo imaging revealed a high intensity in lung lobes (Fig. 1c, d). CFU values were slightly higher but not significantly different in the substrains (CD26/DPP4 ${ }^{+}: 4.49 \pm 2.18$ $\times 10^{10} \mathrm{CFU}, \mathrm{CD} 26 / \mathrm{DPP}^{-}: 2.84 \pm 1.80 \times 10^{10}$ ).

\section{Lung weight and volume}

Lung weight was significantly higher in the animals of the experimental groups (Table 1) than in animals of the control groups. Furthermore, the CD26/DPP4 ${ }^{+}$rats exhibited a significantly lower weight compared to the wild types $(p<0.05)$. Lung volumes showed high variation and, therefore, did not differ in controls and infected lungs (Table 1).

\section{CFU values}

Huge amounts of $P A$ were determined in homogenized lungs, liver and spleen without strain specific differences (Table 2).

\section{Macroscopic results and lung parenchyma of saline treated sham controls}

Lungs of both subtypes showed no signs of hemorrhage or other pathological alterations. Lung parenchma of both genotypes exhibited normally expanded ductus alveolares and alveoli with small septa. No edema was detected. Also the fine structure showed regularly formed air blood barriers as well as intact alveolar epithelial cells type II with numerous lamellar bodies (Fig. 2). Lung parenchyma was well preserved.

\section{Macroscopic results of infected lungs}

The infected lungs clearly showed changes in colour below the visceral pleura (beige, brown, red) resulting from different degrees of infiltration and hemorrhage (Fig. 3a).

\section{Lung parenchyma of infected lungs}

The $P A$-infected rats showed heterogeneous distribution patterns of germs, edema and structural alterations in lungs, due to intratracheal instillation of the bacteria, independent of the genotype. On the light microscopic level lung areas 
ventral
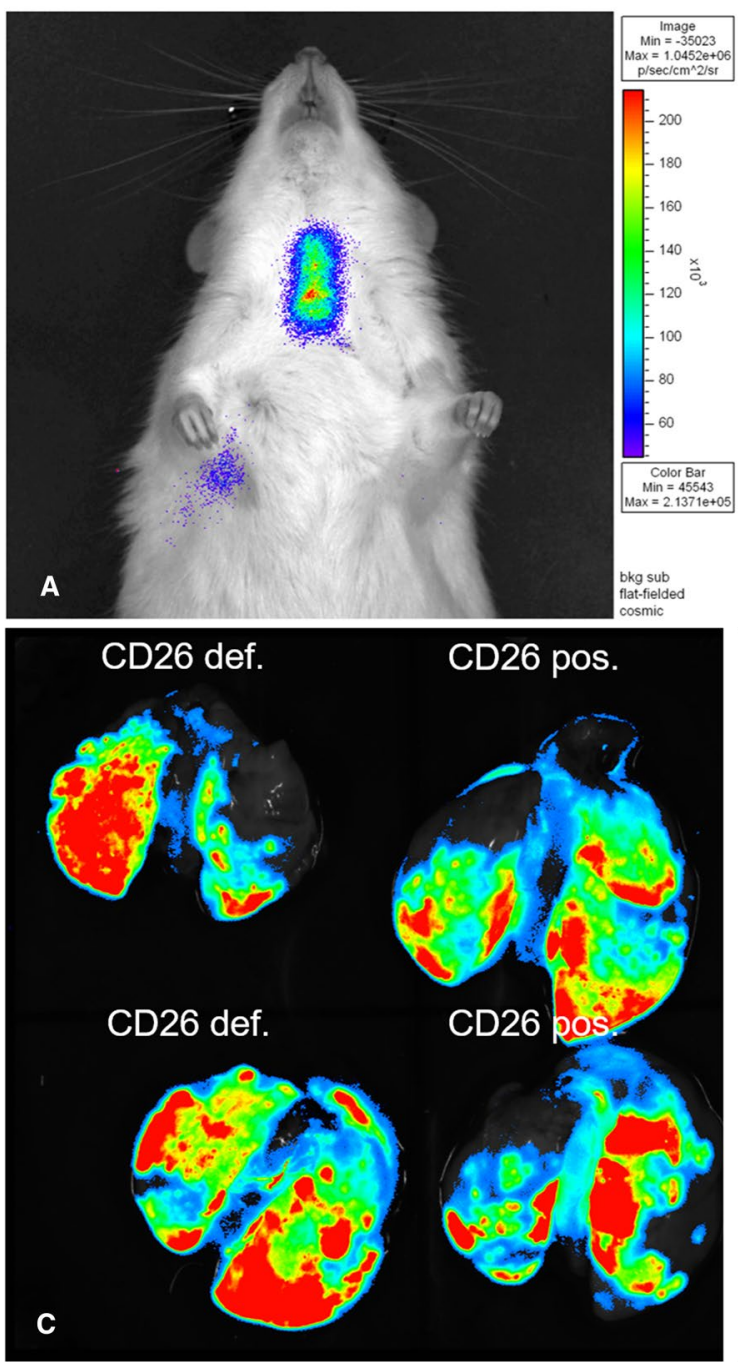

Fig. 1 Pictures captured with the "in vivo imaging system 2000 (IVIS)". In vivo recording of a narcotized rat after intratracheal instillation of $1 \times 10^{10} \mathrm{cfu} P A /$ rat. a Immediately after intratracheal instillation with a strong signal in the trachea and a weak signal in the right lung, b $6 \mathrm{~h}$ after instillation with a strong signal in the left lung and dorsal
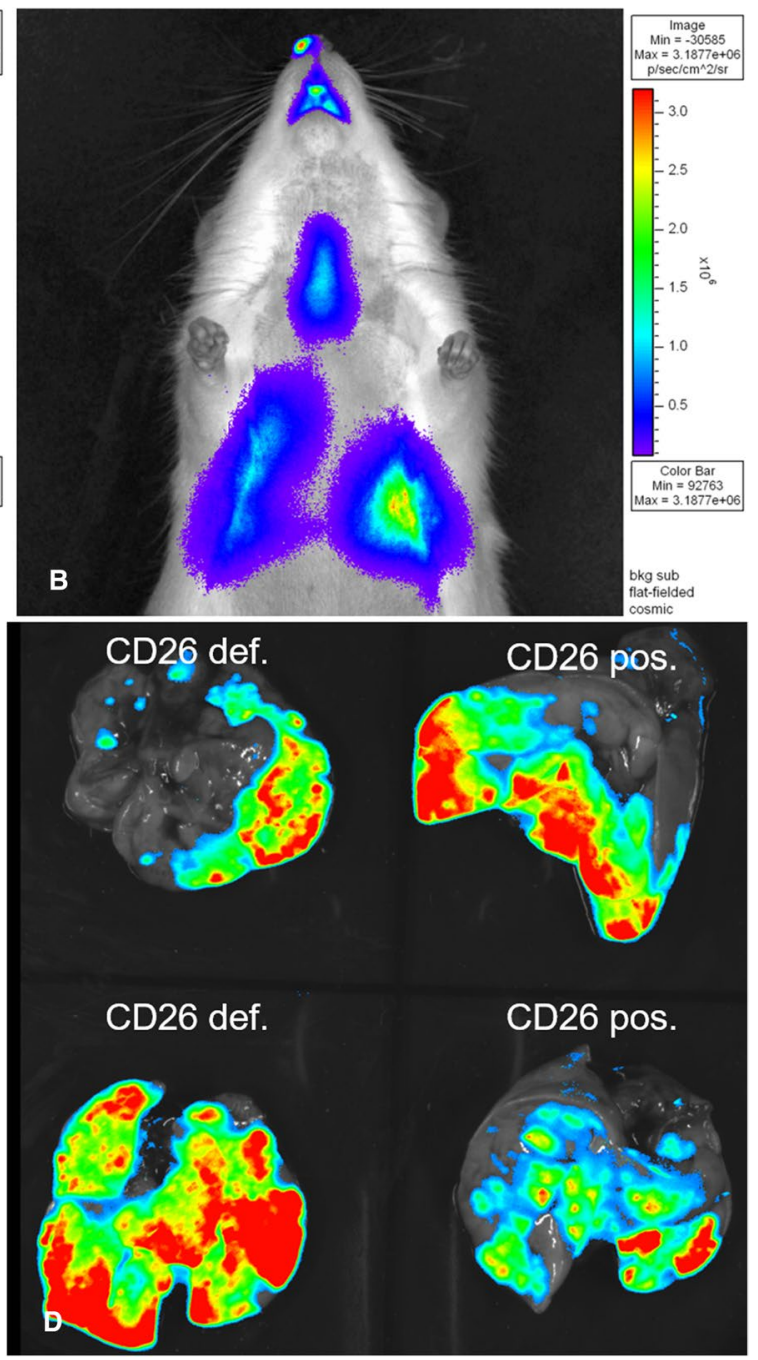

in the oro-nasal region. A moderate signal in the trachea and the right lung is obvious. c, d Ex vivo recordings $6 \mathrm{~h}$ after intratracheal instillation of removed lungs of CD26/DPP4 deficient and positive rats. An inhomogeneous distribution of the germs in the lung lobes is clearly visible
Table 1 Lung weight and volume of controls and infected animals

Table $2 \mathrm{CFU} / \mathrm{g}$ values of $P A$ in liver and spleen of infected animals

\begin{tabular}{llllll}
\hline $\begin{array}{lllll}\text { Genotype, } n=9 \\
\text { Mean } \pm \text { SD }\end{array}$ & \multicolumn{2}{l}{ Saline inoculation } & & PA inoculation & \\
\cline { 2 - 3 } \cline { 5 - 6 } & Weight & Volume & & Weight & Volume \\
\hline CD26/DPP4 $^{+}$ & $0.56 \pm 0.04 \mathrm{~g}$ & $1.31 \pm 0.57 \mathrm{~cm}^{3}$ & & $2.59 \pm 0.23 \mathrm{~g}$ & $2.02 \pm 0.35 \mathrm{~cm}^{3}$ \\
$\mathrm{CD} 26 / \mathrm{DPP} 4^{-}$ & $0.53 \pm 0.05 \mathrm{~g}$ & $1.43 \pm 0.81 \mathrm{~cm}^{3}$ & & $2.07 \pm 0.03 \mathrm{~g}$ & $1.73 \pm 0.25 \mathrm{~cm}^{3}$ \\
\hline
\end{tabular}

\begin{tabular}{|c|c|c|c|}
\hline \multirow[t]{2}{*}{ Genotype, $n=6$} & \multicolumn{3}{|l|}{$6 \mathrm{~h}$ after $\mathrm{PA}$ inoculation } \\
\hline & Lung, Mean \pm SD & Liver, Mean \pm SD & Spleen, Mean \pm SD \\
\hline $\mathrm{CD}^{26 / D P P} 4^{+}$ & $17.1 \times 10^{6} \pm 1.5 \times 10^{6}$ & $20.0 \times 10^{6} \pm 11.3 \times 10^{6}$ & $87.4 \times 10^{6} \pm 60.5 \times 10^{6}$ \\
\hline CD26/DPP4- & $21.5 \times 10^{6} \pm 2.6 \times 10^{6}$ & $31.0 \times 10^{6} \pm 5.1 \times 10^{6}$ & $41.3 \times 10^{6} \pm 28.1 \times 10^{6}$ \\
\hline
\end{tabular}




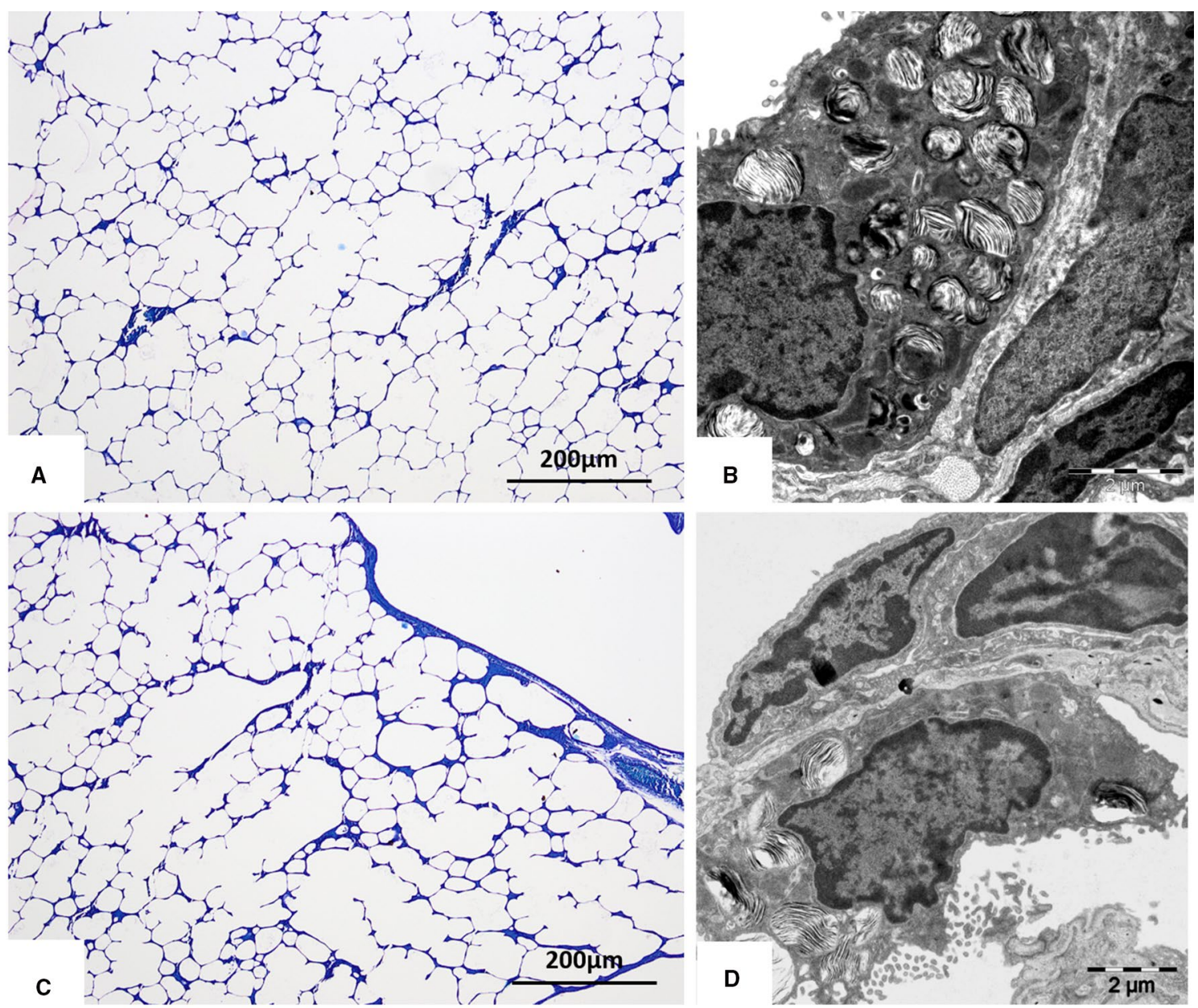

Fig. 2 Lung parenchyma of control rats. CD26/DPP4 positive rat: a light microscopy, b electron microscopy; CD26/DPP4 deficient rat: $\mathbf{c}$ light microscopy, $\mathbf{d}$ electron microscopy

with alveoli strongly or completely filled with edematous liquid alternated with areas exhibiting less pronounced or no edema. Frequently the alveolar fluid included more or less numerous germs and blood cells (Fig. 3b-d). Looking at the non-parenchyma, the wall of bronchi and vessels was largely free of infiltrates (Fig. 4a). Occasionally perivascular edema filled with immune cells was visible (Fig. 4b).

On the electron microscopic level, the alveolar epithelial cells type II (AEII) showed no signs of damage (Fig. 4c, d). However, alveolar edema filled with bacteria was clearly visible frequently (Fig. 4d, e) and the alveolar epithelial surface and capillary endothelium partly exhibited no structural integrity (Fig. 5). Thinning of alveolar epithelium up to denudation of the basement membrane, epithelial fragmentation and constrictions ('blebbing') were often visible as signs of epithelial damage (Fig. 5a-d). Protein rich edema partly containing germs covered damaged alveolar epithelium frequently. Compared to controls (Fig. 6a) cell-cell-connections between alveolar epithelial cells, especially the tight-junctions, were extended and blurred (Fig. 6b). Active and inactive intraalveolar surfactant formations were partly associated with germs (Fig. 6c, d). So $P A$ was found within unilamellar (inactive subtypes) and multilamellar vesicles as well as within tubular myelin (active subtypes). Not infrequently surfactant subtypes and germs were covered with alveolar edematous fluid (Fig. 6c, d). The alveoli were partly filled with indefineable cell debris (Fig. 7a). Alveolar macrophages containing numerous $P A$ partly in apparently dissolving cytoplasm occurred sporadically in the alveolar space (Fig. 7b). In places, the structural integrity of the alveolar septum was abolished (Fig. 7c). A crossing of bacteria in capillaries appeared very rarely. The alveolar space revealed not only alveolar macrophages but also neutrophils containing phagocytosed germs (Fig. 7d). 


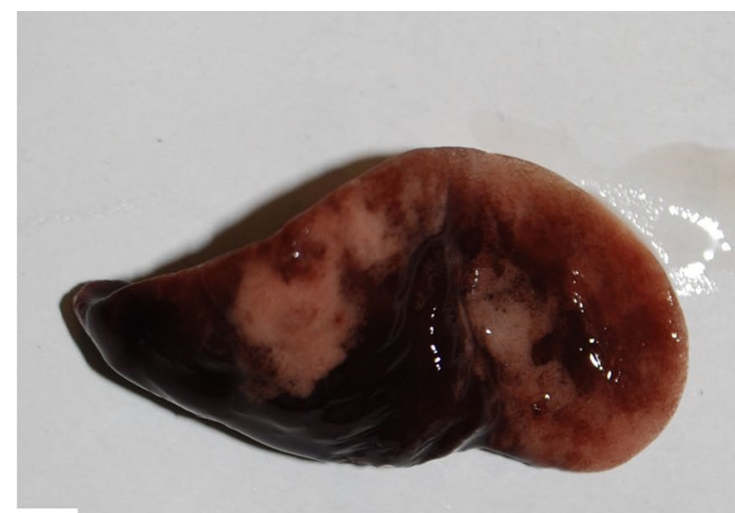

A

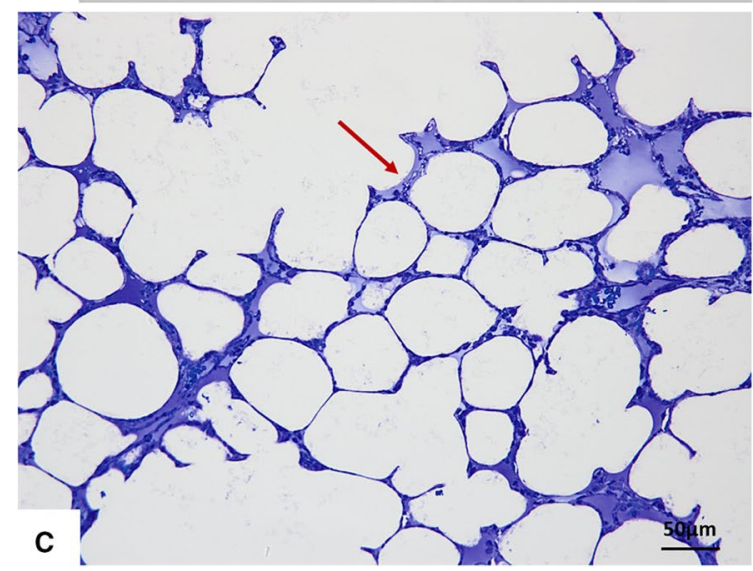

Fig. 3 Morphology and light microscopy of infected lungs $6 \mathrm{~h}$ after infection. a Whole left rat lung. b Lung parenchyma with atelectatic and dilated alveoli. Alveolar edema is irregularly distributed (toluidine-blue staining). c Less pronounced edema $(\searrow$ ) in some alveoli

\section{Stereological results}

\section{Light microscopy (Table 3)}

The $V_{\mathrm{V}}($ alveoli+ducti/par) as a parameter for the airspace distal of the terminal bronchi amounted to $82.31 \pm 6.64 \%$ in $\mathrm{CD} 26 / \mathrm{DPP} 4^{+}$and to $82.35 \pm 8.23 \%$ in $\mathrm{CD} 26 / \mathrm{DPP} 4^{-}$rats $(n=5$, respectively). $P A$ infection did not change significantly the $V_{\mathrm{V}}$ of airspaces $\left(\mathrm{CD} 26 / \mathrm{DPP} 4^{+}: 88.74 \pm 2.55 \%\right.$, CD26/DPP4 ${ }^{-}: 82.51 \pm 9.02 \%, n=6$, respectively). Furthermore, the total volume of airspaces in the controls with values of $1.10 \pm 0.46 \mathrm{~cm}^{3}\left(\mathrm{CD} 26 / \mathrm{DPP} 4^{+}\right)$and $1.06 \pm 0.68 \mathrm{~cm}^{3}$ (DPP4/CD26- ${ }^{-}$was in the same range in both genotypes after $P A$ infection $\left(1.53 \pm 0.21 \mathrm{~cm}^{3}\right.$ and $\left.1.41 \pm 0.20 \mathrm{~cm}^{3}\right)$ without strain specific differences.

The $V_{\mathrm{S}}$-ratio (alv,sept) as a reference space independent parameter for the size of alveoli showed with $16.91 \pm 2.82 \mu \mathrm{m}\left(\mathrm{CD} 26 / \mathrm{DPP}^{+}\right)$and $16.64 \pm 3.23 \mu \mathrm{m}$ $\left(\mathrm{CD} 26 / \mathrm{DPP}^{-}\right)$in controls comparable values. After infection, a significant reduction in alveolar size independent of the genotype was found $\left(\mathrm{CD} 26 / \mathrm{DPP} 4^{+}: 13.62 \pm 1.33 \mu \mathrm{m}\right.$;

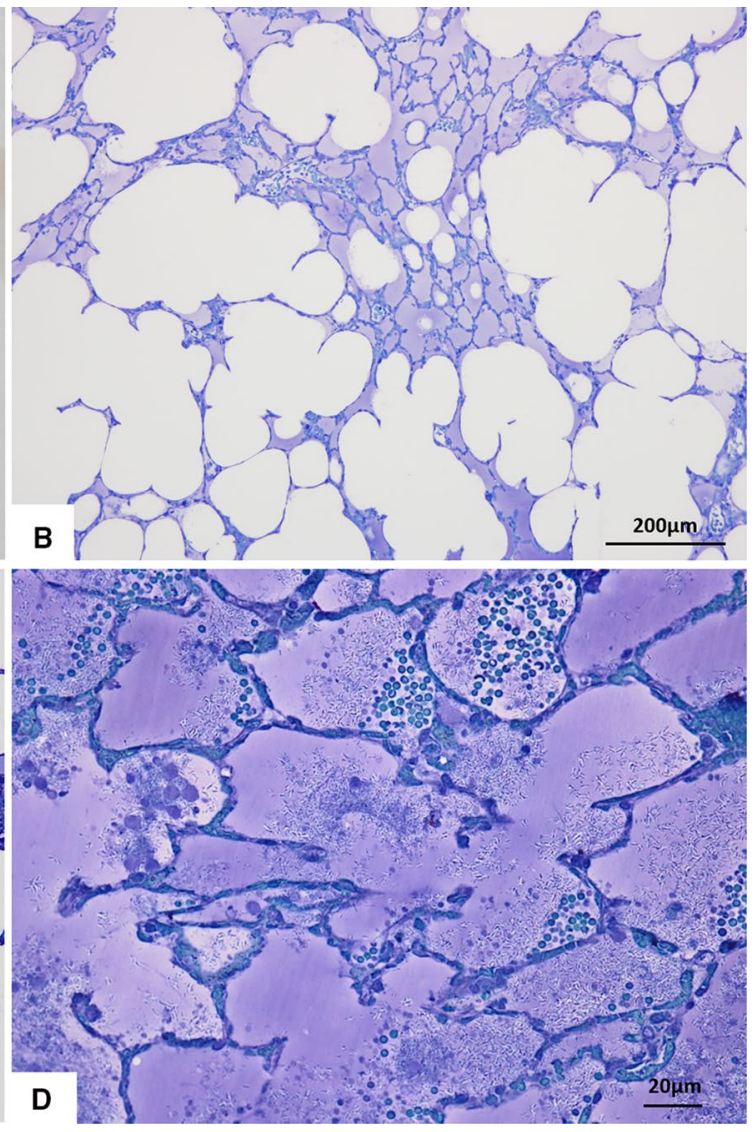

(toluidine-blue staining). d Part of lung parenchyma showing germs and inflammatory cells in alveoli completely filled with edematous fluid (toluidine-blue)

CD26/DPP4 $\left.{ }^{-}: 13.87 \pm 1.31 \mu \mathrm{m}\right)$ without strain dependent differences.

The degree of edema in alveoli and ductus alveolares was determined by $V_{\mathrm{v}}$ (edema/airspace). After infection in CD26/ $\mathrm{DPP}^{+}{ }^{+}$rats $27 \pm 14 \%$ and in the $\mathrm{CD} 26 / \mathrm{DPP}^{-}$rats $13 \pm 10 \%$ of alveolar airspace was filled with alveolar fluid. There was a significant difference between both genotypes $(p<0.05)$. The total edema in airspaces ( $V$ (edema/lung)) amounted to $0.44 \pm 0.34 \mathrm{~mm}^{3}$ in wild types and to $0.22 \pm 0.15 \mathrm{~mm}^{3}$ in CD26/DPP4- animals each after infection. There was no significance because of the high variation.

Furthermore, genotype specific differences were found in the portion of PA in edematous fluid. $28 \pm 9 \%$ of edematous airspaces in CD26/DPP4 ${ }^{+}$lungs and $15 \pm 9 \%$ in the CD26/DPP4 $4^{-}$lungs were filled with $P A(p<0.05)$. The septal surface fraction covered with edematous fluid amounted to $39.46 \pm 1.00 \%$ in CD26/DPP4 ${ }^{+}$rats $(n=3)$ and to $30.06 \pm 7.89 \%$ in CD26/DPP4 ${ }^{-}$rats $(n=4)(p<0.057)$.

The $V_{\mathrm{V}}(\mathrm{septa} / \mathrm{par})$ amounted to $12.80 \pm 4.14 \%$ and to $14.80 \pm 5.48 \%$ in wild type and CD26/DPP4 ${ }^{-}$controls. $P A$-instillation did not change the septal volume densities 


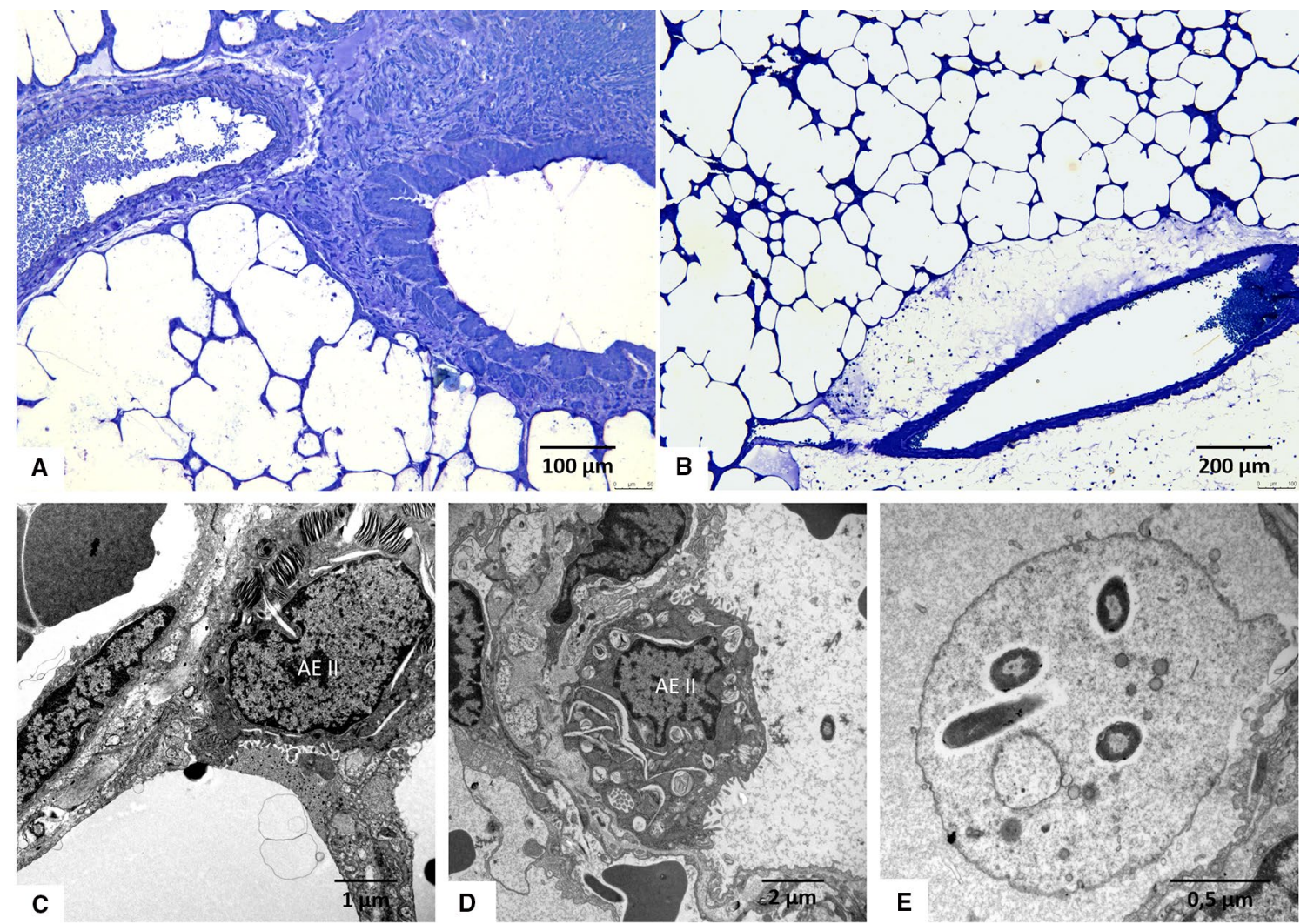

Fig. 4 Light and electron microscopy of infected lungs $6 \mathrm{~h}$ after infection. a Bronchus and artery without peribronchial edema (toluidine-blue staining). b Perivascular edema with inflammatory cells (toluidine-blue staining). c Intact alveolar epithelial type II cells

$(10.89 \pm 1.70 \%$ and $12.67 \pm 1.38 \%)$. However, the absolute septal volume ( $V$ (septa/lung)) was significantly changed after infection $\left(\mathrm{CD} 26 / \mathrm{DPP}^{+}: 0.16 \pm 0.07 \mathrm{~cm}^{3}\right.$ to $0.27 \pm 0.06 \mathrm{~cm}^{3}$; $\mathrm{CD} 26 / \mathrm{DPP}^{-}: 0.16 \pm 0.04 \mathrm{~cm}^{3}$ to $\left.0.23 \pm 0.02 \mathrm{~cm}^{3}\right)$.

The $S_{\mathrm{V}}($ septa/par) exhibited comparable values with $0.037 \pm 0.008 \mu \mathrm{m}^{2} / \mu \mathrm{m}^{3}$ vs $0.039 \pm 0.011 \mu \mathrm{m}^{2} / \mu \mathrm{m}^{3}$ in both control groups. Interestingly, after infection the septal surface density significantly increased to $0.053 \pm 0.004 \mu \mathrm{m}^{2} /$ $\mu^{3}$ in CD26/DPP4 ${ }^{+}$and to $0.052 \pm 0.004 \mu^{2} / \mu^{3}$ in CD26/ DPP4 ${ }^{-}$rats. The total septal surface increased significantly from $466.64 \pm 113.45 \mathrm{~cm}^{2}$ to $938.52 \pm 174.73 \mathrm{~cm}^{2}$ in CD26/ $\mathrm{DPP}^{+}$and from $458.17 \pm 191.82 \mathrm{~cm}^{2}$ to $834.89 \pm 51.37 \mathrm{~cm}^{2}$ in deficient rats. No genotype specific differences were found.

Mean alveolar septal thickness $(\tau)$ in controls was $7.12 \pm 2.0 \mu \mathrm{m}$ in lungs of CD26/DPP4 ${ }^{+}$rats and $6.97 \pm 2.76 \mu \mathrm{m}$ in lungs of CD26/DPP4 ${ }^{-}$rats. There was a significant decrease in the infected lungs to $4.17 \pm 0.79 \mu \mathrm{m}$ in $\mathrm{CD} 26 / \mathrm{DPP}^{+}{ }^{+}$rats and to $4.91 \pm 0.34 \mu \mathrm{m}$ in $\mathrm{CD} 26 /$ DPP4- ${ }^{-}$rats without genotype specific differences.
(AEII) covered by unilamellar vesicles (ulv) and tubular myelin (tmy). d Intact AEII and intralveolar edema. e Protein rich intraalveolar edema containing germs and inactive intraalveolar surfactant (unilamellar vesicles)

\section{Electron microscopy (Table 3)}

After infection the $V_{\mathrm{v}}$ (epi/septa) was significantly $(p<0.01)$ lower than in control groups independent of the genotype $\left(\mathrm{CD} 26 / \mathrm{DPP}^{+}: 56.93 \pm 9.00 \%, n=9\right.$ vs $63.62 \pm 6.01 \%$,

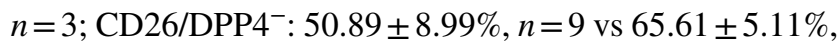
$n=3)$. The $\mathrm{V}_{\mathrm{V}}$ (endo/septa) exhibited comparable values independent of the genotype or infection (CD26/DPP4 ${ }^{+}$: $8.09 \pm 3.22 \%$ vs $7.62 \pm 2.59 \%, \mathrm{CD}_{26} / \mathrm{DPP}^{-}: 7.20 \pm 2.36 \%$ vs $6.14 \pm 0.18 \%)$. The $\mathrm{V}_{\mathrm{V}}$ (interstitium/septa) exhibited significantly $(p<0.02)$ higher values in the infected group compared to the controls independent of the genotype (CD26/ $\mathrm{DPP}^{+}: 34.98 \pm 10.23 \%$ vs $28.76 \pm 3.43 \%, \mathrm{CD} 26 / \mathrm{DPP} 4^{-}$: $41.91 \pm 8.28 \%$ vs $28.25 \pm 4.83 \%$ ).

Alveolar epithelial damage characterized as loss of continuity, thickening of the basement membrane as well as constrictions, blebbing, swelling or loss of the alveolar epithelium was evaluated as percentage of damaged alveolar epithelial surface in relation to the whole surface. After infection, $41.80 \pm 13.30 \%$ in the CD26/DPP4 ${ }^{+}$and $42.70 \pm 5.60 \%$ of the alveolar epithelial surface in the CD26/ 

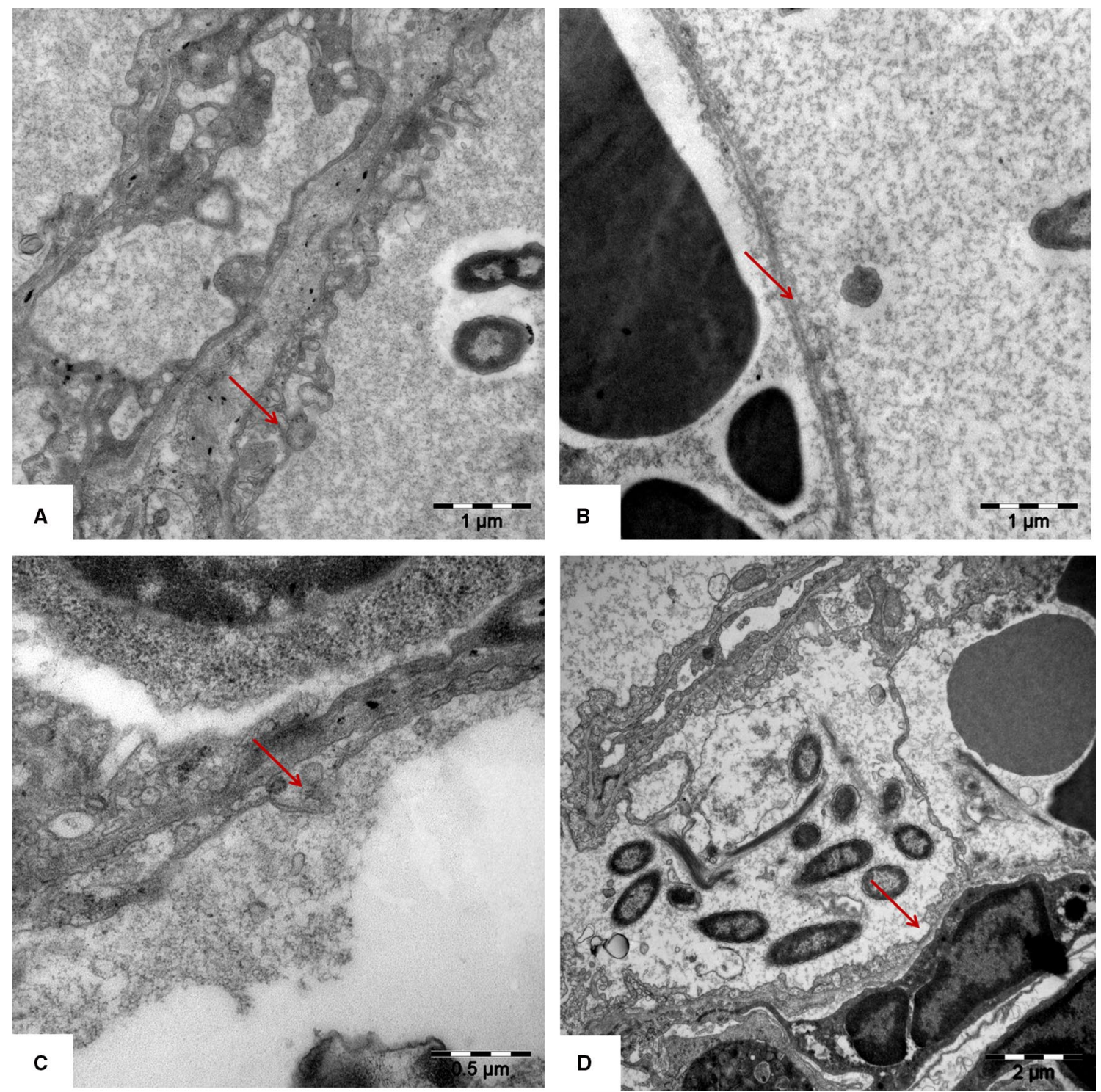

Fig. 5 Electron microscopy of infected lungs $6 \mathrm{~h}$ after infection. a Alveolar septum with interstitial edema covered with alveolar edematous fluid. Germs are visible. Bulging out of a part of alveolar epithelial cell (blebbing) ( $\searrow$ ). b Loss of epithelial continuity by interruption of epithelial lining, basement membrane is denuded. ( $)$. c

$\mathrm{DPP}^{-}{ }^{-}$rats was damaged. Furthermore, $36.79 \pm 12.8 \%$ and $30.06 \pm 7.9 \%$ of the epithelial surface were covered with edematous fluid in CD26/DPP4 ${ }^{+}$and in CD26/DPP4 ${ }^{-}$rats.

In control groups the mean thickness of air-bloodbarrier was $\tau_{\mathrm{c}}=2.84 \pm 0.05 \mu \mathrm{m}$ in $\mathrm{CD} 26 / \mathrm{DPP}^{+}{ }^{+}$rats and $\tau_{\mathrm{c}}=2.39 \pm 0.34 \mu \mathrm{m}$ in CD26/DPP4- rats. After infection the $\tau_{\mathrm{c}}$ was $1.42 \pm 0.30 \mu \mathrm{m}$ in CD26/DPP4 ${ }^{+}$rats and $\tau_{\mathrm{c}}=1.35 \pm 0.32 \mu \mathrm{m}$ in deficient rats. There are significantly lower values in the infected group than in the control.

Discontinuous alveolar epithelium $(\searrow$ ) is covered by alveolar protein rich fluid. d Partly thinned alveolar epithelium, partly lifted from the basement membrane. Germs and cell detritus within the alveolar fluid are visible

\section{Expression of SP-A and SP-D}

No alterations were found in mRNA expression of SP-A and SP-D in lungs of controls and infected rats independent of the subtype (Table 4). The SP-A protein expression seemed to be higher in infected animals compared to controls (Fig. 8a), however, a quantitative evaluation was not possible due to the small sample size. The SP-D protein expression did not differ between controls and infected animals (Fig. 8b). 

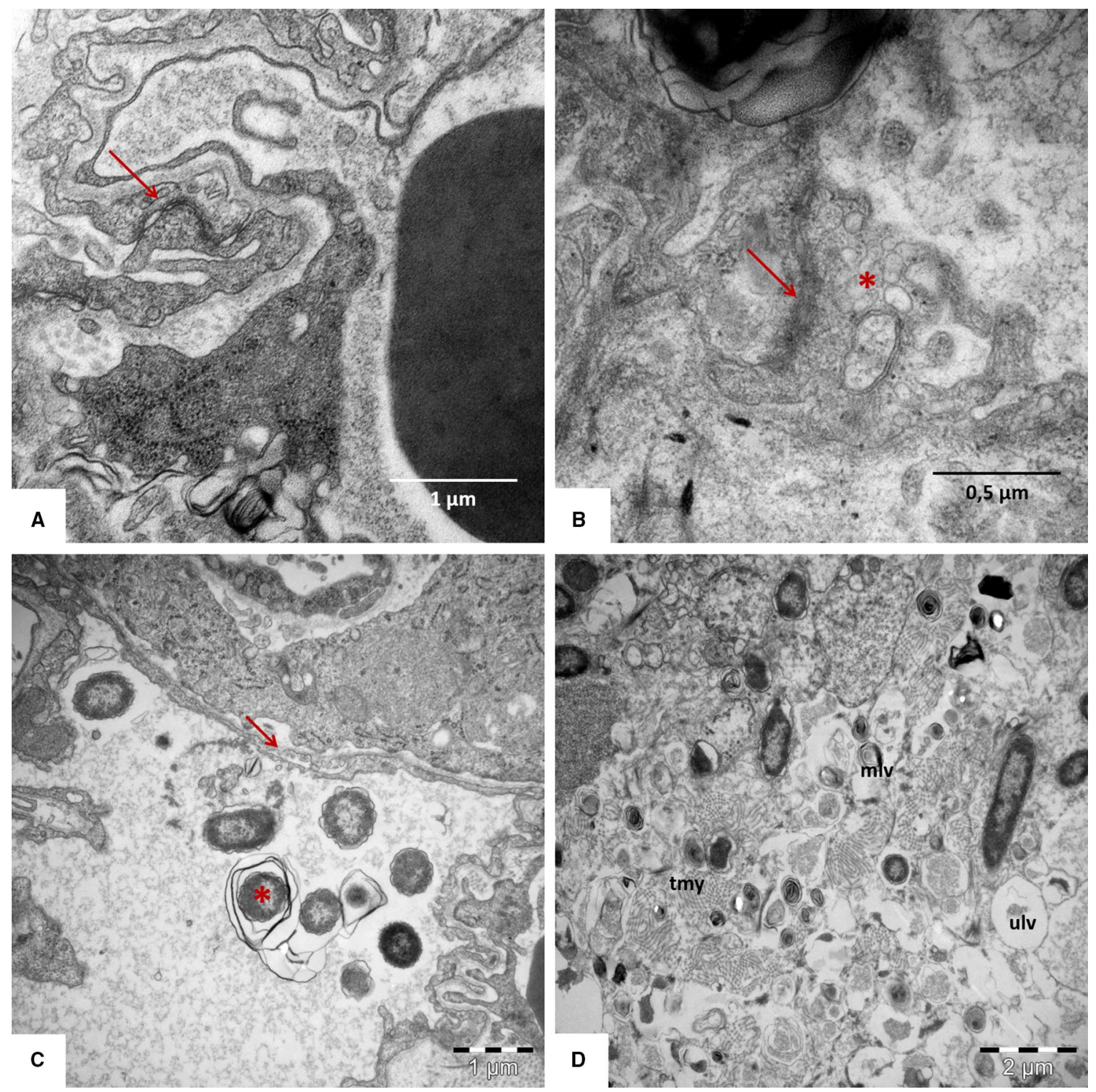

Fig. 6 Electron microscopy of infected lungs $6 \mathrm{~h}$ after infection. Alveolar epithelium with regular cell-cell contacts ( $)$, control group. b-d Infection group. b Partly swollen alveolar epithelium with dissolved cell-cell contacts $(\searrow)$. Apparent partly desquamation of alveolar epithelium (*). c Differently thick alveolar epithelium laying

\section{Discussion}

\section{Bacterial distribution}

On the base of murine experiments done with a lower bacterial dose and resulting in an inhomogeneous pulmonary distribution without structural damage [9], we chose a higher infective dose for rats to get more information about the place of transfer to the vascular bed and the pattern of $P A$-induced structural damage. The used dose caused a pronounced clinical picture. We classified the rats' condition independent of the genotype as moderately troubled

on a partly discontinuous basement membrane ( $\searrow$, alveolar edema, germs partly in contact with multilamellar $(*)$ and unilamellar vesicles. d Multiple germs surrounded by active and inactive surfactant formations, tubular myelin (tmy), lamellar body like structures (lbl), multilamellar vesicle (mlv), unilamellar vesicle (ulv)

$2 \mathrm{~h}$ after instillation and as profoundly disturbed $6 \mathrm{~h}$ after instillation, indicating that the animals could not cope sufficiently with the infection. Therefore, we stopped the experiment there, sacrificed the rats and analyzed their lungs. The high CFU numbers implicate a strong bacterial proliferation in the lungs, which obviously could not be controlled by the defense system, although we saw a lot of alveolar macrophages and neutrophils with engulfed bacteria, indeed partly destroyed. Neutrophils are crucial in host immune defense against PA-infections [36]. The used strain TBCF10839 is able to sustain phagocytosis by neutrophils and is even able to proliferate within immune cells [37]. 


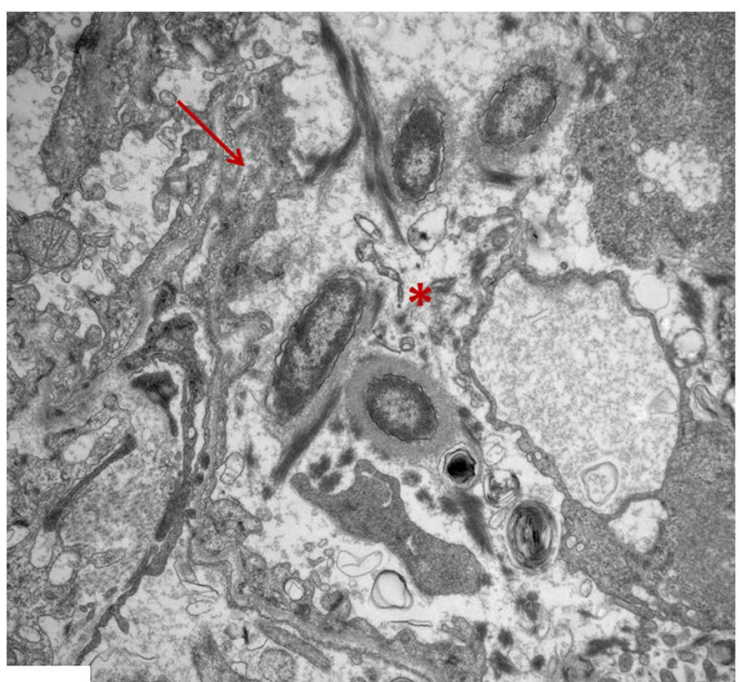

A

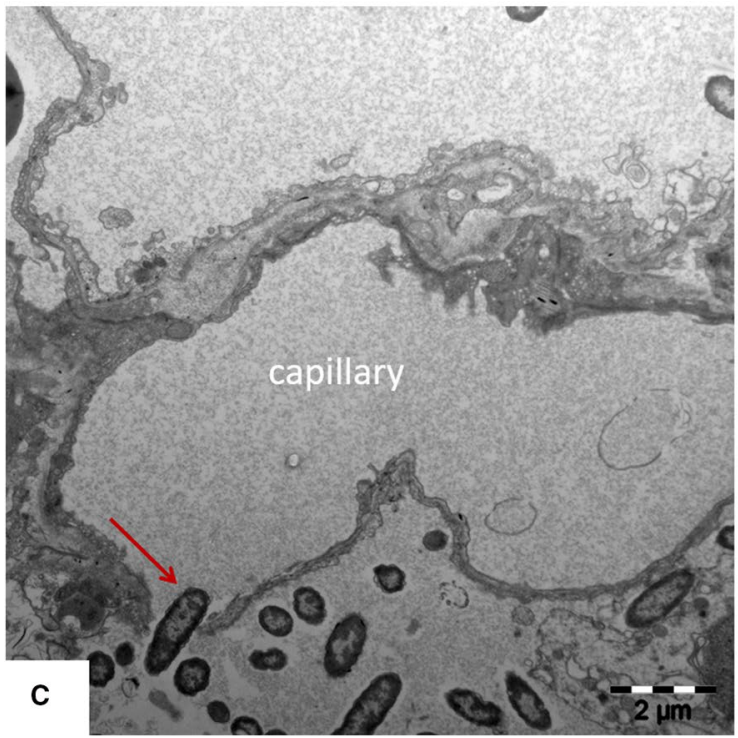

Fig. 7 Electron microscopy of infected lungs $6 \mathrm{~h}$ after infection. Alveolar septa with pronounced epithelial damage ( $)$, intraalveolar edema and germs. Due to strong infection classification of tissue is partly impossible, cell detritus (*). b Damaged alveolar macrophage

However, bacterial division stages in defense cells were not clearly visible, probably because the normally exponential bacterial growth gets to the stationary phase. The bacteria had not been digested in the defense cells, which is in accordance with phagocytosis experiments with isolated leucocytes, in which the non-piliated $P A$ survived in phagosomes and, furthermore, disrupted the phagosomal membrane, grew and divided in the cytoplasm, which was proved by electron microscopy [5].

However, we did not find $P A$ taken up by AEII, as seen before in a mouse model $1 \mathrm{~h}$ after inoculation [9]. The main cause may be that generally only a minority of adherent non-piliated bacteria were internalized by epithelial cells.
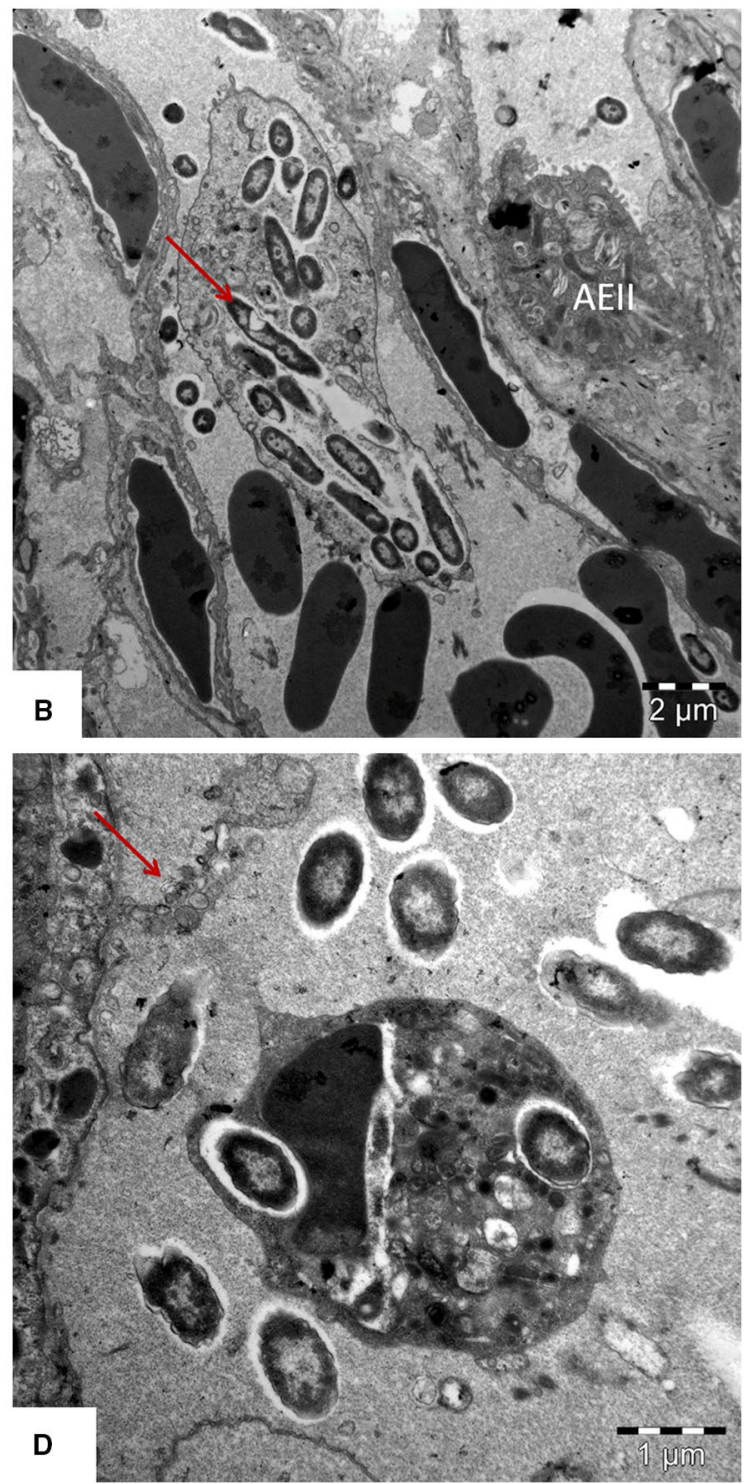

with numerous engulfed $P A$, intraalveolar edema, haemorrhage and a alveolar epithelial cell type II (AEII) are visible. c Discontinuous alveolar septum with transseptal migration of PA $(\searrow)$. d Neutrophil with incorporated $P A$, epithelial damage $(\searrow)$, intraalveolar edema

Adherence assays showed a comparable weak attachment to different epithelial cells [5]. Chi et al. demonstrated that piliated bacteria bind better to A549 cells and survive longer within intracellular membrane bound vacuoles than non-piliated bacteria, which are rapidly killed and digested after internalization [38]. Therefore, the loss of forming pili [4] may lead to a reduced or unsuccessful uptake of $P A$ by alveolar epithelial cells. However, complete digestion of a few bacteria cannot be excluded, too.

Germs were predominantly observed in the alveolar space and partly within edematous fluid. Of note, a remarkable systemic spread of bacteria into liver and spleen with numbers even higher than in the lung occurred, suggesting an 
Table 3 Stereological parameters of controls and infected rats (mean \pm SD)

\begin{tabular}{|c|c|c|c|c|c|c|}
\hline & $\begin{array}{l}\text { Controls, DPP4/ } \\
\text { CD } 26^{+} \text {rats }\end{array}$ & $\begin{array}{l}\text { Controls, CD26/ } \\
\text { DPP4- rats }\end{array}$ & $\begin{array}{l}\text { Infected CD26/ } \\
\mathrm{DPP}^{+} \text {rats }\end{array}$ & $\begin{array}{l}\text { Infected CD26/ } \\
\mathrm{DPP}^{-} \text {rats }\end{array}$ & $\begin{array}{l}p \text { values, controls } \\
\text { vs. infected rats }\end{array}$ & $\begin{array}{l}p \text { values, inf. CD26/ } \\
\text { DPP4 }^{+} \text {vs. inf. } \\
\text { CD26/DPP4 }{ }^{-} \text {rats }\end{array}$ \\
\hline Light microscopy & $n=6$ & $n=6$ & $n=6$ & $n=6$ & & \\
\hline$V_{\mathrm{V}}($ airspace/par) $(\%)$ & $82.31 \pm 6.64$ & $82.35 \pm 8.23$ & $88.74 \pm 2.55$ & $82.51 \pm 9.02$ & 0.33 & 0.27 \\
\hline $\begin{array}{l}V \text { (airspace/ } \\
\text { lung) }\left(\mathrm{cm}^{3}\right)\end{array}$ & $1.10 \pm 0.46$ & $1.06 \pm 0.68$ & $1.53 \pm 0.21$ & $1.41 \pm 0.20$ & 0.06 & 0.68 \\
\hline $\begin{array}{l}V \text { s-ratio(alv/sept }) \\
\quad(\mu \mathrm{m})\end{array}$ & $16.91 \pm 2.82$ & $16.64 \pm 3.23$ & $13.62 \pm 1.33$ & $13.87 \pm 1.31$ & 0.0001 & 0.4388 \\
\hline $\begin{array}{l}V_{\mathrm{v}}(\text { edema/air- } \\
\text { space })(\%)\end{array}$ & 0 & 0 & $27 \pm 14$ & $13 \pm 10$ & $<0.0001$ & 0.14 \\
\hline$V($ edema/lung $)\left(\mathrm{cm}^{3}\right)$ & 0 & 0 & $0.44 \pm 0.34$ & $0.22 \pm 0.15$ & 0.0002 & 0.14 \\
\hline$S_{\mathrm{S}}($ edema/septa) $(\%)$ & 0 & 0 & $39.79 \pm 12.83$ & $30.06 \pm 7.89$ & $<0.0001$ & 0.36 \\
\hline$V_{\mathrm{v}}($ septa/par $)(\%)$ & $12.80 \pm 4.14$ & $14.80 \pm 5.48$ & $10.89 \pm 1.70$ & $12.67 \pm 1.38$ & 0.21 & 0.24 \\
\hline$V_{\mathrm{V}}($ septa/lung $)\left(\mathrm{cm}^{3}\right)$ & $0.16 \pm 0.07$ & $0.16 \pm 0.04$ & $0.27 \pm 0.06$ & $0.23 \pm 0.02$ & 0.0027 & 0.38 \\
\hline $\begin{array}{l}S_{\mathrm{V}}(\text { septa/par })\left(\mu \mathrm{m}^{2} /\right. \\
\left.\mu \mathrm{m}^{3}\right)\end{array}$ & $0.037 \pm 0.01$ & $0.039 \pm 0.01$ & $0.053 \pm 0.01$ & $0.052 \pm 0.01$ & 0.0002 & 0.96 \\
\hline $\mathrm{S}$ (septa/lung) $\left(\mu \mathrm{m}^{2}\right)$ & $466.64 \pm 113.45$ & $458.17 \pm 191.82$ & $938.52 \pm 174.73$ & $834.89 \pm 51.37$ & $<0.0001$ & 0.42 \\
\hline Septal thickness $(\mu \mathrm{m})$ & $7.12 \pm 2.0$ & $6.97 \pm 2.76$ & $4.17 \pm 0.79$ & $4.91 \pm 0.34$ & 0.0042 & 0.69 \\
\hline Electron microscopy & $n=3$ & $n=3$ & $n=9$ & $n=9$ & & \\
\hline$V_{\mathrm{V}}($ epi/septa) $(\%)$ & $50.89 \pm 8.99$ & $56.93 \pm 9.00$ & $63.62 \pm 6.01$ & $65.61 \pm 5.11$ & 0.0138 & 0.62 \\
\hline$V_{\mathrm{V}}($ endo/septa $)(\%)$ & $8.09 \pm 3.22$ & $7.20 \pm 2.36$ & $7.62 \pm 2.59$ & $6.14 \pm 0.18$ & 0.54 & 0.35 \\
\hline $\begin{array}{l}V_{\mathrm{V}}(\text { interstitium/septa }) \\
(\%)\end{array}$ & $34.98 \pm 10.23$ & $41.91 \pm 8.28$ & $28.76 \pm 3.43$ & $28.25 \pm 4.83$ & 0.022 & 0.43 \\
\hline $\begin{array}{l}S_{\mathrm{S}}(\text { damaged surf/ } \\
\text { septa) }(\%)\end{array}$ & 0 & 0 & $41.80 \pm 13.30$ & $42.70 \pm 5.60$ & $<0.0001$ & 0.99 \\
\hline $\begin{array}{l}\text { Thickness blood/air } \\
\text { barrier }(\mu \mathrm{m})\end{array}$ & $2.84 \pm 0.05$ & $2.39 \pm 0.34$ & $1.42 \pm 0.30$ & $1.35 \pm 0.32$ & $<0.0001$ & 0.12 \\
\hline
\end{tabular}

Table 4 Genexpression of SP-A and SP-D in controls and infected animals

\begin{tabular}{|c|c|c|c|c|}
\hline \multirow[t]{2}{*}{ Genotyp } & \multicolumn{2}{|c|}{ Controls, $\Delta \Delta C_{\mathrm{q}}$ values, Mean $\pm \mathrm{SD}$} & \multicolumn{2}{|c|}{$\begin{array}{l}\text { PA infected animals, } \Delta \Delta C_{\mathrm{q}} \text { values, } \\
\text { Mean } \pm \mathrm{SD}\end{array}$} \\
\hline & SP-A mRNA & SP-D mRNA & SP-A mRNA & SP-D mRNA \\
\hline $\begin{array}{l}\mathrm{CD} 26 / \mathrm{DPP} 4^{+} \\
n=3, \text { each }\end{array}$ & $0.073 \pm 0.338$ & $-0.358 \pm 0.641$ & $0.067 \pm 0.735$ & $-0.412 \pm 0.590$ \\
\hline $\mathrm{CD}^{26 / \mathrm{DPP}} 4^{-}, n=3$, each & $-0.073 \pm 0.119$ & $0.358 \pm 0.226$ & $-0.857 \pm 0.272$ & $-0.295 \pm 0.701$ \\
\hline
\end{tabular}

early and rapid transfer in the blood (septicemia). Taken together, we found germs in the alveolar and bronchial space as well as in defense cells, but neither clearly in the alveolar septa, nor in the peribronchial or perivascular space, nor in the capillaries or vessels. Although we used the systematic random sampling method to guarantee that each part of the lung has an equal chance of being evaluated and scrutinized ultrastructurally ultra-thin sections of numerous tissue blocks. One possible explanation for the missing structural correlate may be a very fast crossing of bacteria and a very short retention period of germs in blood vessels caused additionally by increased blood flow during exsanguination. An additional washout of intravascular bacteria may be caused by cutting the lung into slices and blocks as a result of squeezing.

\section{Structural damage}

The pronounced alveolar edema seen partially light and electron microscopically as well as the severe damage in lung parenchyma are morphological correlates for dyspnea, and increased nasal secretion and constitute the remarkable increase in lung weight. Moreover, thinning and loss of continuity of alveolar septa combined with epithelial 

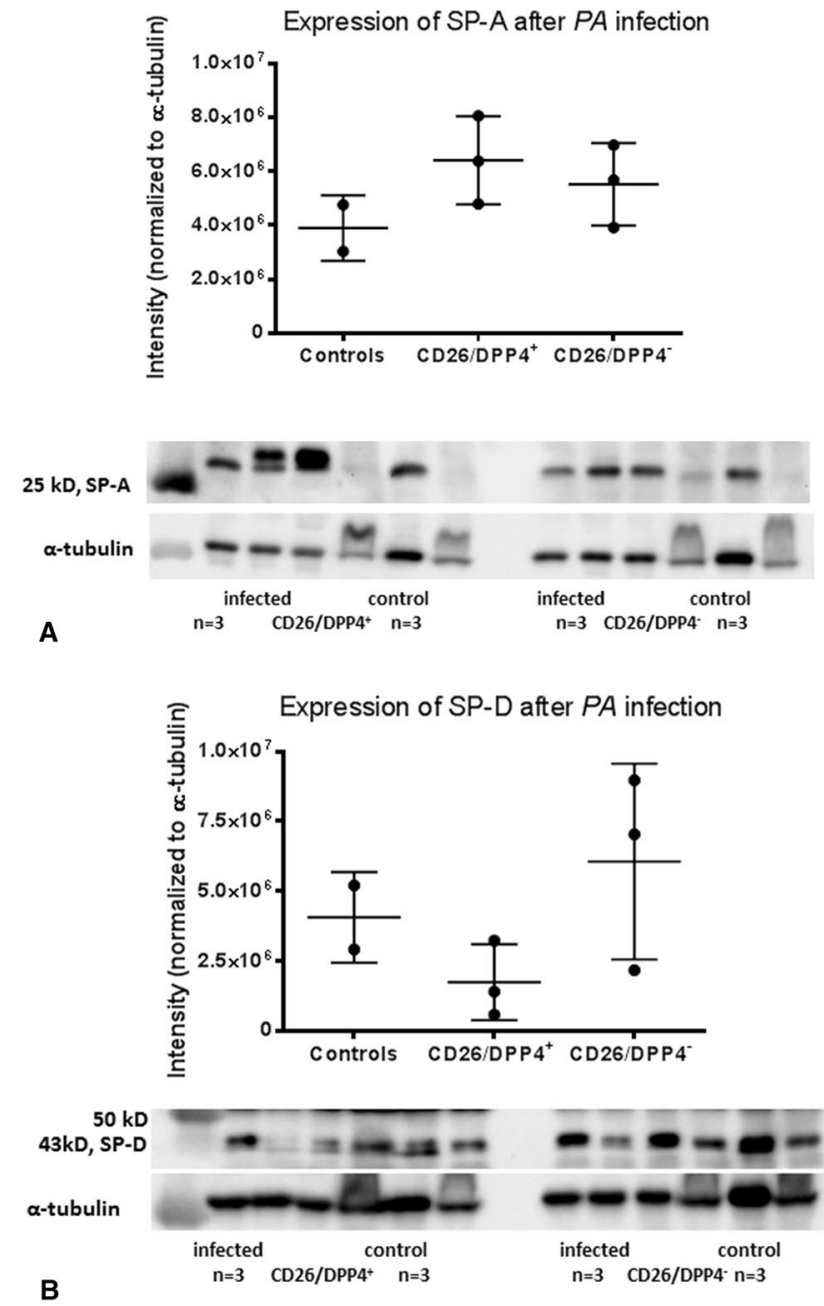

Fig. 8 Western Blot analysis: densitometric results and blot lines for a SP-A and b SP-D. Line 1 shows the molecular weight marker for western blotting, respectively

damage limited the gas exchange capacity. Interestingly, we determined an increase in septal surface at unchanged septal volume indicating an abolition of septal continuity, not visible in other $P A$ infection models [5, 6, 8, 39-43]. Thus, the infective dose as well as the selected $P A$ strain and its virulence factors influence the degree of inflammation as well as structural alterations. The used $P A$ strain has a fully functional Type III secretion system, which enables to express and secrete different exotoxins such as ExoS, ExoT, ExoU and ExoY [36] as well as the Type II secretion system, elastase, LPS, lipid A, and O-polysaccharid (O-Antigen) [5]. The alveolar edema may be the morphological consequence of an increased permeability of the alveolar epithelial barrier caused by exoenzyme $\mathrm{S}$ (ExoS). So $8 \mathrm{~h}$ after instillation of ExoS producing $P A$ mutants not only a dissemination in the blood occurred, but also a significant increase in lung water [39]. Additionally, cell-cell-interactions, especially tight-junctions, may be opened by lysis of proteins of the occludin- and claudin-group, which are necessary for junctional stability $[44,45]$. ExoS-expressing strains changed the distribution of the tight junction proteins ZO- 1 and occludin and were able to transmigrate across polarized airway epithelial monolayers [46].

Furthermore, the $P A$ exoproducts exotoxin A (ExoA) and elastase induced increased epithelial paracellular permeability in primary isolates of AEII and Madin-Darby canine kidney (MDCK) cells, caused by a depletion of two tight junctional proteins, ZO-1 and ZO-2 [41]. The authors suggested that $P A$ elastase increases alveolar epithelial permeability by damaging tight junction-associated proteins. Although ExoA is not primarily responsible for lung injury [39], it may prevent junction protein synthesis [41].

Furthermore, activation of neutrophils may contribute to basement membrane destruction and increased permeability of the alveolar-capillary barrier. Neutrophil mediators such as elastase can cause severe epithelial damage in infected organs [36] and are able to degrade epithelial junctional proteins [47]. Thus, epithelial damage as well as the opening of tight junctions caused the differently pronounced alveolar edema, but also enhanced systemic transfection [48]. The additional increased alveolar size may be the result of a more pronounced overextension or instability of septa as result of degradation of elastic fibres by neutrophil and $P A$ elastases $[49,50]$.

Ultrastructurally, we also saw morphological relations between $P A$ and subtypes of the pulmonary surface active agent (surfactant). $P A$ infections are capable of attacking pulmonary surfactant on many different fronts [51]. A higher portion of unilamellar vesicles and lower portion of tubular myelin is considered as morphological correlate of an increased conversion from large to small aggregates [52]. However, we saw areas with predominantly unilamellar vesicles (Fig. 4c), as such with tubular myelin (Fig. 6d), but did not determine the subtypes quantitatively. In vitro studies have shown that the incubation of surfactant with protease IV affects the biophysical function of surfactant [53]. So incubating surface tension lowering large aggregates (tubular myelin, lamellar body like vesicles) obtained from the bronchoalveolar lavage fluid (BALF) with PA protease IV inhibited the surface tension-lowering function of LA [53]. Because of the additionally described degradation of SP-B [51], the lipid adsorption to the air-liquid interface may be restricted and surface tension increased, leading more frequently to alveolar collapse and problems with breathing as seen in the infected groups.

Additionally, intact surfactant prevents alveolar fluid accumulation [54]. Thus, degradation of surfactant reduces its anti-edematous capacity and may enhance alveolar edema [55].

Not only $P A$ elastase, but also neutrophil elastase is responsible for the degradation of phospholipids and 
immunomodulating surfactant proteins (collectines) [13, 51], resulting possibly in a reduced uptake of $P A$ first by macrophages and then by neutrophils, because of lack or insufficiency of the induced opsonin effect. SP-D, isolated from the lavage fluid of silica-treated rats, significantly enhanced the uptake of different strains of $P A$ by rat alveolar macrophages seen by means of both fluorescence and electron microscopy [56]. Studies with collectin-knockout mice showed that phagocytosis of bacteria by alveolar macrophages was decreased $6 \mathrm{~h}$ after infection compared with wild types [12]. Our molecular biological studies with only small sample numbers showed no infection or genotype dependent changes in collectin gene expression $6 \mathrm{~h}$ after infection. Because of the high standard deviation using three animals per group already a justifiable increase of animals would not led to significant alterations. We assume that a $P A$ induced expression immediately after infection was followed by an increased instability of collectin mRNA induced by $P A$ secretion products or synthesis exhaustion so that $6 \mathrm{~h}$ after infection an increased gene expression is not detectable. The elevated SP-A levels in both genotypes might be the result of an increased protein expression. However, a statistical test was not possible because of the small sample numbers. The SP-D values were in the same range in all groups. The lack of significant differences in the SP content could as well be due to the degradation of collectins by PA secreted virulence factors as already described by others. So PA elastase degrades SP-A and, therefore, reduced the phagocytosis of the bacteria in mouse lungs [57]. Furthermore, SP-D is also modified by elastase leading to a $35 \mathrm{kD}$ fragment, in which the degree of degradation depends on dose, time and temperature [58]. The $35 \mathrm{kD}$ fragment was not detectable in our blots, may be because the concentration was still too low. Additionally, incubation of cell-free BALF with PA protease IV resulted in degradation of both collectins [53].

It cannot be denied that the degree of structural damage and the bad healthy condition may be partly the result of PA induced alterations in the biophysical and immunological effects of the surfactant system. However, our data in conjunction with other results show, that $P A$ predominantly degrades the intraalveolar surfactant. The surfactant secreting AEII are structurally intact and may be not affected.

\section{CD26/DPP4 dependent differences}

Except for the less pronounced edema and lower lung weight as well as the lower portion of PA in edematous fluid, no CD26/DPP4 dependent morphological and PA distribution differences were evaluated in this study. However, as described by others, CD26/DPP4 is also involved in aggravation of inflammation. They found (1) a CD26 mediated costimulation of T-cells combined with production of the proinflammatory interleukin-2 (IL-2) [59], (2) a CD26 mediated co-stimulation of $\mathrm{CD}^{+} \mathrm{T}$ cells, which exert cytotoxic effects predominantly via TNF- $\alpha$ [18], (3) a DPP4 dependent cleavage of the chemokine substrate LD78ß into a very efficient monocyte attractant, enhancing lymphocyte and monocyte chemotactic activity [60], and (4) a CD26/DPP4inhibitor dependent increase of the anti-inflammatory peptide VIP (Vasointestinal peptide) in rats [61], diminishing inflammatory response $[15,21]$. Furthermore, using different CD26/DPP4 inhibitors signs of inflammation were reduced in different lung disease models [22, 62, 63]. Not at all, our group found a reduced inflammation in CD26/ DPP4- rats [24]. CD26/DPP4 deficiency caused less pronounced recruitment of activated T-lymphocytes and eosinophils [24], less pronounced neutrophil alveolar invasion [64] and influenced cleavage of different cytokines thereby affecting the inflammatory response as well [14].

However, in our infection model the CD26/DPP4 deficiency resulted predominantly in less pronounced edema, which confirms a possible attenuation of inflammation in CD26/DPP4 deficient animals as described in the asthma model.

The modest genotype dependent differences in the structural preservation after $P A$ infection could have the following reasons: (1) CD26/DPP4 has lesser influence on the bacterial toxins, which are partly responsible for the structural damage. (2) The pronounced structural alterations induced by infection and inflammation mask possible genotype dependent differences. (3) CD26/DPP4 performs negative and positive feedback during inflammation, so that different effects cancel each other. (4) Our methodological equipment does not capture potential differences in inflammation signs.

Acknowledgements The authors thank Sabine Fiedler, Damaris Leemhuis and Melanie Bornemann for their excellent technical assistance as well as Dr. Dirk Wedekind for his support and instruction in the IVIS and Caroline Meinshausen for proofreading.

Author contributions AS, AM conceived and designed the study. AS, MN wrote, edited and reviewed the manuscript. AM, JS edited and reviewed the manuscript. AS, AM, MN, JS carried out the experiments, researched and analyzed the data. AS, AM, MN, JS gave final approval for publication. AS takes full responsibility for the work as a whole, including the study design, access to data and the decision to submit and publish the manuscript.

\section{Compliance with ethical standards}

Microbiologic monitoring during breeding and maintenance of the rats were done according to FELASA recommendations, all procedures performed on rats were approved by the local authorities (LAVES, Oldenburg, Germany, file nr.: 0815-24).

Conflict of interest The authors have no conflicts of interest to declare. 


\section{References}

1. Micek ST, Kollef MH, Torres A, et al. Pseudomonas aeruginosa nosocomial pneumonia: impact of pneumonia classification. Infect Control Hosp Epidemiol. 2015;36:1190-7.

2. Lin CK, Kazmierczak BI. Inflammation: a double-edged sword in the response to pseudomonas aeruginosa infection. J. Innate. Immun. 2017;9:250-61.

3. Tacconelli E, Magrini N, Kahlmeter G, Singh N. Global priority list of antibiotic-resistant bacteria to guide research, discovery, and development of new antibiotics. World Health Organ 2017;1-7.

4. Chang YS, Klockgether J, Tummler B. An intragenic deletion in pilQ leads to nonpiliation of a Pseudomonas aeruginosa strain isolated from cystic fibrosis lung. FEMS Microbiol Lett. 2007;270:201-6.

5. Klockgether J, Miethke N, Kubesch P, et al. Intraclonal diversity of the Pseudomonas aeruginosa cystic fibrosis airway isolates TBCF10839 and TBCF121838: distinct signatures of transcriptome, proteome, metabolome, adherence and pathogenicity despite an almost identical genome sequence. Environ Microbiol. 2013;15:191-210.

6. Wolbeling F, Munder A, Kerber-Momot T, et al. Lung function and inflammation during murine Pseudomonas aeruginosa airway infection. Immunobiology. 2011;216:901-8.

7. Wolbeling F, Munder A, Stanke F, Tummler B, Baumann U. Headout spirometry accurately monitors the course of Pseudomonas aeruginosa lung infection in mice. Respiration. 2010;80:340-6.

8. Munder A, Wolbeling F, Kerber-Momot T, et al. Acute intratracheal Pseudomonas aeruginosa infection in cystic fibrosis mice is age-independent. Respir Res. 2011;12:148.

9. Schmiedl A, Kerber-Momot T, Munder A, Pabst R, Tschernig $\mathrm{T}$. Bacterial distribution in lung parenchyma early after pulmonary infection with Pseudomonas aeruginosa. Cell Tissue Res. 2010;342:67-73.

10. Wright JR. Host defense functions of pulmonary surfactant. Biol Neonate. 2004;85:326-32.

11. Sano H, Kuroki Y. The lung collectins, SP-A and SP-D, modulate pulmonary innate immunity. Mol Immunol. 2005;42:279-87.

12. Giannoni E, Sawa T, Allen L, Wiener-Kronish J, Hawgood S. Surfactant proteins A and D enhance pulmonary clearance of Pseudomonas aeruginosa. Am J Respir Cell Mol Biol. 2006;34:704-10.

13. Mariencheck WI, Alcorn JF, Palmer SM, Wright JR. Pseudomonas aeruginosa elastase degrades surfactant proteins A and D. Am J Respir Cell Mol Biol. 2003;28:528-37.

14. Klemann C, Wagner L, Stephan M, von Hörsten S. Cut to the chase: a review of CD26/dipeptidyl peptidase-4's (DPP4) entanglement in the immune system. Clin Exp Immunol. 2016;185:1-21.

15. Mentlein R, Dipeptidyl-peptidase IV. (CD26) — role in the inactivation of regulatory peptides. Regul Pept. 1999;85:9-24.

16. Strieter RM, Belperio JA, Keane MP. Cytokines in innate host defense in the lung. J Clin Invest. 2002;109:699-705.

17. Tanaka T, Kameoka J, Yaron A, Schlossman SF, Morimoto C. The costimulatory activity of the $\mathrm{CD} 26$ antigen requires dipeptidyl peptidase IV enzymatic activity. Proc Natl Acad Sci USA. 1993;90:4586-90.

18. Hatano R, Ohnuma K, Yamamoto J, Dang NH, Morimoto C. CD26-mediated co-stimulation in human CD8(+) T cells provokes effector function via pro-inflammatory cytokine production. Immunology. 2013;138:165-72.

19. Ikushima H, Munakata Y, Iwata S, et al. Soluble CD26/dipeptidyl peptidase IV enhances transendothelial migration via its interaction with mannose 6-phosphate/insulin-like growth factor II receptor. Cell Immunol. 2002;215:106-10.

20. Kruschinski C, Skripuletz T, Bedoui S, et al. CD26 (dipeptidylpeptidase IV)-dependent recruitment of T cells in a rat asthma model. Clin Exp Immunol. 2005;139:17-24.

21. Jungraithmayr W, De Meester I, Matheeussen V, et al. Inhibition of CD26/DPP IV attenuates ischemia/reperfusion injury in orthotopic mouse lung transplants: the pivotal role of vasoactive intestinal peptide. Peptides. 2010;31:585-91.

22. Kawasaki T, Chen W, Htwe YM, Tatsumi K, Dudek SM. DPP4 inhibition by sitagliptin attenuates LPS-induced lung injury in mice. Physiol: Am J Physiol Lung Cell Mol; 2018.

23. Schade J, Schmiedl A, Kehlen A, et al. Airway-specific recruitment of T cells is reduced in a CD26-deficient F344 rat substrain. Clin Exp Immunol. 2009; 158:133-42.

24. Schmiedl A, Krainski J, Schwichtenhovel F, et al. Reduced airway inflammation in CD26/DPP4-deficient F344 rats is associated with altered recruitment patterns of regulatory $\mathrm{T}$ cells and expression of pulmonary surfactant proteins. Clin Exp Allergy. 2010;40:1794-808.

25. Zhao G, Jiang Y, Qiu H, et al. Multi-organ damage in human dipeptidyl peptidase 4 transgenic mice infected with middle east respiratory syndrome-coronavirus. PLoS One. 2015;10:e0145561.

26. Thompson NL, Hixson DC, Callanan H, et al. A Fischer rat substrain deficient in dipeptidyl peptidase IV activity makes normal steady-state RNA levels and an altered protein. Use as a liver-cell transplantation model. Biochem J. 1991;273(Pt 3):497-502.

27. DiGiandomenico A, Rao J, Harcher K, et al. Intranasal immunization with heterologously expressed polysaccharide protects against multiple Pseudomonas aeruginosa infections. Proc Natl Acad Sci USA. 2007;104:4624-9.

28. Choi KH, Kumar A, Schweizer HP. A 10-min method for preparation of highly electrocompetent Pseudomonas aeruginosa cells: application for DNA fragment transfer between chromosomes and plasmid transformation. J Microbiol Methods. 2006;64:391-7.

29. Munder A, Wolbeling F, Klockgether J, Wiehlmann L, Tummler B. In vivo imaging of bioluminescent Pseudomonas aeruginosa in an acute murine airway infection model. Pathog Dis. 2014;72:74-7.

30. Munder A, Krusch S, Tschernig T, et al. Pulmonary microbial infection in mice: comparison of different application methods and correlation of bacterial numbers and histopathology. Exp Toxicol Pathol. 2002;54:127-33.

31. Munder A, Zelmer A, Schmiedl A, et al. Murine pulmonary infection with Listeria monocytogenes: differential susceptibility of BALB/c, C57BL/6 and DBA/2 mice. Microbes Infect. 2005;7:600-11.

32. Morton DB, Griffiths PH. Guidelines on the recognition of pain, distress and discomfort in experimental animals and an hypothesis for assessment. Vet Rec. 1985;116:431-6.

33. Hsia CC, Hyde DM, Ochs M, Weibel ER. An official research policy statement of the American Thoracic Society/European Respiratory Society: standards for quantitative assessment of lung structure. Am J Respir Crit Care Med. 2010;181:394-418.

34. Tschanz SA, Burri PH, Weibel ER. A simple tool for stereological assessment of digital images: the STEPanizer. J Microsc. 2011;243:47-59.

35. Ochs M. Stereological analysis of acute lung injury. Eur Respir Rev. 2006;15:115-21.

36. Sadikot RT, Blackwell TS, Christman JW, Prince AS. Pathogenhost interactions in Pseudomonas aeruginosa pneumonia. Am J Respir Crit Care Med. 2005;171:1209-23.

37. Tummler B. Unusual mechanism of pathogenicity of Pseudomonas aeruginosa isolates from patients with cystic fibrosis. Infection. 1987;15:311-2. 
38. Chi E, Mehl T, Nunn D, Lory S. Interaction of Pseudomonas aeruginosa with A549 pneumocyte cells. Infect Immun. 1991;59:822-8.

39. Kudoh I, Wiener-Kronish JP, Hashimoto S, Pittet JF, Frank D. Exoproduct secretions of Pseudomonas aeruginosa strains influence severity of alveolar epithelial injury. Am J Physiol. 1994;267:L551-6.

40. Tang H, Kays M, Prince A. Role of Pseudomonas aeruginosa pili in acute pulmonary infection. Infect Immun. 1995;63:1278-85.

41. Azghani AO. Pseudomonas aeruginosa and epithelial permeability: role of virulence factors elastase and exotoxin A. Am J Respir Cell Mol Biol. 1996;15:132-40.

42. Fleiszig SM, Wiener-Kronish JP, Miyazaki H, et al. Pseudomonas aeruginosa-mediated cytotoxicity and invasion correlate with distinct genotypes at the loci encoding exoenzyme S. Infect Immun. 1997;65:579-86.

43. Comolli JC, Hauser AR, Waite L, Whitchurch CB, Mattick JS, Engel JN. Pseudomonas aeruginosa gene products PilT and PilU are required for cytotoxicity in vitro and virulence in a mouse model of acute pneumonia. Infect Immun. 1999;67:3625-30.

44. Furuse M, Fujita K, Hiiragi T, Fujimoto K, Tsukita S. Claudin-1 and -2 : novel integral membrane proteins localizing at tight junctions with no sequence similarity to occludin. J Cell Biol. 1998;141:1539-50.

45. Gonzalez-Mariscal L, Betanzos A, Nava P, Jaramillo BE. Tight junction proteins. Prog Biophys Mol Biol. 2003;81:1-44.

46. Soong G, Parker D, Magargee M, Prince AS. The type III toxins of Pseudomonas aeruginosa disrupt epithelial barrier function. J Bacteriol. 2008;190:2814-21.

47. Johnson ER, Matthay MA. Acute lung injury: epidemiology, pathogenesis, and treatment. J Aerosol Med Pulm Drug Del. 2010;23:243-52

48. Rejman J, Di GS, Bragonzi A, Conese M. Pseudomonas aeruginosa infection destroys the barrier function of lung epithelium and enhances polyplex-mediated transfection. Hum Gene Ther. 2007; 18:642-52.

49. Katsha AM, Ohkouchi S, Xin H, et al. Paracrine factors of multipotent stromal cells ameliorate lung injury in an elastase-induced emphysema model. Mol Ther. 2011;19:196-203.

50. Ginzberg HH, Cherapanov V, Dong Q, et al. Neutrophil-mediated epithelial injury during transmigration: role of elastase. Am J Physiol Gastrointest Liver Physiol. 2001;281:G705-17.

51. Beatty AL, Malloy JL, Wright JR. Pseudomonas aeruginosa degrades pulmonary surfactant and increases conversion in vitro. Am J Respir Cell Mol Biol. 2005;32:128-34.

52. Veldhuizen RA, Inchley K, Hearn SA, Lewis JF, Possmayer F. Degradation of surfactant-associated protein B (SP-B) during in vitro conversion of large to small surfactant aggregates. Biochem. J. 1993;295(Pt 1):141-7.
53. Malloy JL, Veldhuizen RA, Thibodeaux BA, O'Callaghan RJ, Wright JR. Pseudomonas aeruginosa protease IV degrades surfactant proteins and inhibits surfactant host defense and biophysical functions. Am J Physiol Lung Cell Mol Physiol. 2005;288:L409-18.

54. Orgeig S, Morrison JL, Daniels CB. Evolution, development, and function of the pulmonary surfactant system in normal and perturbed environments. Comp Physiol. 2015;6:363-422.

55. Ochs M, Nenadic I, Fehrenbach A, et al. Ultrastructural alterations in intraalveolar surfactant subtypes after experimental ischemia and reperfusion. Am J Respir Crit Care Med. 1999;160:718-24.

56. Restrepo CI, Dong Q, Savov J, Mariencheck WI, Wright JR. Surfactant protein D stimulates phagocytosis of Pseudomonas aeruginosa by alveolar macrophages. Am J Respir Cell Mol Biol. 1999;21:576-85.

57. Kuang Z, Hao Y, Walling BE, Jeffries JL, Ohman DE, Lau GW, Bose S. Pseudomonas aeruginosa elastase provides an escape from phagocytosis by degrading the pulmonary surfactant proteinA. PLoS ONE 2011;6(11):e27091.

58. Alcorn JF, Wright JR. Degradation of pulmonary surfactant protein D by Pseudomonas aeruginosa elastase abrogates innate immune function. J Biol Chem. 2004;279:30871-9.

59. Morimoto C, Schlossman SF. The structure and function of CD26 in the T-cell immune response. Immunol Rev. 1998;161:55-70.

60. Proost P, Menten P, Struyf S, Schutyser E, De MI, Van DJ. Cleavage by CD26/dipeptidyl peptidase IV converts the chemokine LD78beta into a most efficient monocyte attractant and CCR1 agonist. Blood. 2000;96:1674-80.

61. Said SI. VIP as a modulator of lung inflammation and airway constriction. Am Rev Respir Dis. 1991;143:S22-4.

62. Suzuki T, Tada Y, Gladson S, et al. Vildagliptin ameliorates pulmonary fibrosis in lipopolysaccharide-induced lung injury by inhibiting endothelial-to-mesenchymal transition. Respir Res. 2017;18:177.

63. Jang JH, Yamada Y, Janker F, et al. Anti-inflammatory effects on ischemia/reperfusion-injured lung transplants by the cluster of differentiation 26/dipeptidylpeptidase 4 (CD26/DPP4) inhibitor vildagliptin. J Thorac Cardiovasc Surg. 2017;153:713-24.

64. Forssmann U, Stoetzer C, Stephan M, et al. Inhibition of CD26/ dipeptidyl peptidase IV enhances CCL11/eotaxin-mediated recruitment of eosinophils in vivo. J. Immunol. 2008;181:1120-7.

Publisher's Note Springer Nature remains neutral with regard to jurisdictional claims in published maps and institutional affiliations. 